\title{
Technology Prospects and the Cross-Section of Stock Returns
}

\author{
Po-Hsuan Hsu \\ Department of Finance, University of Connecticut \\ Dayong Huang \\ Department of Accounting and Finance, University of North Carolina at Greensboro
}

Forthcoming at Journal of Empirical Finance

This version: August 13, 2009

$\dagger$ We are grateful to two anonymous reviewers, Peter Schotman (the associate editor), and Theo J. Vermaelen (the editor), whose insightful comments lead to a much improved version of this article. We also thank Ronald Balvers, Carmelo Giaccotto, Li Gu, Chung-Ming Kuan, Dongmei Li, Claudia Moise, Ralitsa Petkova, Krista Schwarz, Maria Vassalou, Neng Wang, Jialin Yu, and the workshop participants at the Institute of Economics in Academia Sinica, 2008 FMA Annual Meeting, and 2009 NTU IEFA Conference for their valuable comments. Po-Hsuan Hsu is especially indebted to Andrew Ang, Charles M. Jones, and John B. Donaldson for their guidance during his doctoral study. Brian Hentz and Yangchun Chu provides valuable research assistance. We also acknowledge the 2008 FMA Annual Meeting Best Paper Award in Investments sponsored by AAII. All errors remain our own. For correspondence: Po-Hsuan Hsu, Department of Finance, School of Business, University of Connecticut, 2100 Hillside Road, Storrs, CT 06269. Tel: (860) 486-2774, and email: Paul.Hsu@business.uconn.edu. 


\title{
Technology Prospects and the Cross-Section of Stock Returns
}

\author{
Abstract \\ In an economy with time-varying investment opportunities, the changes in technology prospects \\ affect aggregate consumption and individual firms' future dividends, and may lead to systematic \\ risk. We construct a technology factor to track the changes in technology prospects measured by \\ U.S. aggregate patent shocks. Empirical results show that this factor helps to explain consumption \\ growth as well as asset pricing models, and results in significant risk premium.
}

JEL classification: E44; G11; O30

Keywords: Factor models; patents; technological innovations; tracking portfolios 


\section{Introduction}

The idea that technological innovations can explain stock returns is occupying an increasingly important role in the asset pricing literature. Some recent studies focus on the role of aggregate, permanent technology shocks in macroeconomic dynamics and stock returns, ${ }^{1}$ while other studies inspect the effects of various technologies on the cross-sectional variation of stock returns. ${ }^{2}$ No study, however, has analyzed how investors' expectation of aggregate technology level ("technology prospects," hereafter) affects stock returns. In this paper, we aim to examine if technology prospects help to explain stock returns and if the market grants relevant risk premium. This research question is important because the stock prices are determined not only by current technology state but also by the investors' and managers' anticipation of future technological progress.

In an intertemporal economy, time-variant technology prospects affect periodic optimal consumption and thus enter into the pricing kernel. Based on the permanent income hypothesis (Friedman, 1957) and aggregate budget constraint (Campbell, 1993), investors' current consumption depends not only on their current wealth but also on expected future income. Since aggregate technological growth drives up productivity (Solow, 1957) and has persistent or even permanent effect on future output, technology prospects should be positively related with aggregate consumption. According to Merton's (1973) intertemporal capital asset pricing model (ICAPM), all economic variables related to consumption growth may act as systematic risk factors in the the stochastic discount factor $(\mathrm{SDF})$ and affect expected asset returns. ${ }^{3}$ On the other hand, when

\footnotetext{
${ }^{1}$ Lettau (2003), Panageas and Yu (2006), and Kaltenbrunner and Lochstoer (2008) model the effect of technology shocks on market returns and premia. Hsu (2009) finds that technology shocks, measured by patent data and R\&D data, have strong predictive power for market returns and premia. Other relevant studies include Papanikolaou (2008) and Pastor and Veronesi (2008).

${ }^{2} \mathrm{~A}$ partial list of studies on the adjustment costs in production functions includes Gomes, Kogan, and Zhang (2003), Zhang (2005), and Gala (2006). On the other hand, Pakes (1985) finds that firms' patents and R\&D expenses have positive impacts on their stock returns using a micro data set composed of 120 firms over an 8-year period. Apedjinou and Vassalou (2004) find that corporate innovations can explain expected stock returns, especially the momentum phenomenon.

${ }^{3}$ Motivated by the ICAPM, Chen, Roll, and Ross (1986) and Chen (1991) inspect if the production growth, default premium, term premium, short-term interest rate, inflation, and market dividend yield can explain stock returns as they all affect consumption growth. Recent ICAPM-based studies consider aggregate productivity shocks (Balvers and Huang, 2007a), real money growth (Balvers and Huang, 2007b), and size premium as well as value premium (Petkova, 2006; Guo, Savickas, Wang, and Yang, 2007).
} 
technology prospects change, different firms' expected productivity and cash flows rise to different extents, which could give birth to the cross-sectional variation of stock returns.

We empirically test if the changes in technology prospects work as a systematic risk factor in the SDF and whether this factor is priced. We use U.S. patent shocks constructed by Hsu (2009) as a proxy for aggregate technological innovations. Then, we use the tracking portfolio method proposed in Lamont (2001) to construct a technology factor that measures the changes in technology prospects. ${ }^{4}$ We project future technological innovations on current excess returns of base assets and control variables. The coefficient-weighted returns of these base assets constitute a return-based technology factor that tracks the changes in technology prospects. We find that the proposed factor is independent of common risk factors as well as recession indicators, and is able to explain contemporaneous consumption growth. Our findings are consistent with the consumption-based motivation and hint at the unique role of technology prospects in economy.

We follow Cochrane $(1996,2001)$ to examine the risk loading of the technology factor in the SDF and the price of technology risk in the sample period 1981Q4-2007Q3. We find that the technology factor carries significantly negative loading and significantly positive premium, suggesting that the technology factor helps to price assets and itself is also priced. The ICAPM with the technology factor is able to explain over $30 \%$ of the cross-sectional variation of FamaFrench (1993) 25 portfolios, 10 momentum portfolios, and 10 R\&D intensity portfolios. ${ }^{5}$ When we implement a conditional test, the ICAPM is able to explain over $50 \%$ of the variation. Even at the presence of size, book-to-market, and momentum factors, the technology factor still significantly helps to price these testing assets. The statistic and economic significance of the technology factor is not superseded by other consumption risk factors such as consumption growth and cay. These

\footnotetext{
${ }^{4}$ This approach has been widely used in the construction of risk factors such as news about future gross domestic product (GDP) growth (Vassalou, 2003) and expected volatility (Ang, Hordrick, Xing, and Zhang, 2006).

${ }^{5}$ Since Jegadeesh and Titman (1993), it has been well documented that stocks with higher returns in the past (i.e. high-momentum stocks) outperform stocks with lower returns in the past. On the other hand, recent empirical studies indicate that firms' R\&D activities increase subsequent stock returns (e.g. Lev and Sougiannis, 1996; Chan, Lakonishok, and Sougiannis, 2001; Eberhart, Maxwell, and Siddique, 2004; Li, 2007).
} 
findings survive several robustness checks, including a test with a longer sample period back to 1963.

We would like to clarify that the technology factor proposed in this study is distinct from the Solow residual (1957) from several perspectives: First, the technology factor measures the changes in investor's expectation of future technological progress, while the Solow residual is about realized productivity shocks. The Solow residual includes all shocks unexplained by labor and capital, but those shocks could be temporary and irrelevant to technological development. Basu and Fernald (2002) argue that productivity shocks and technology shocks are distinct concepts and perform empirical differences.

This study may contribute to the asset pricing literature from the following perspectives. We show that technological innovations can affect the asset prices through expectation, in addition to realization. Moreover, we use the patent data to better measure technological innovations and, hence, better understand their effect in the cross-section of stock returns. Lastly, we find that technology risk explains a part of the return spread driven by momentum, R\&D intensity, and investment intensity. Our findings therefore provide a technology-based explanation for the cross-section of stock returns, yet further investigation is called to show why technology prospects covariate with stock returns.

The rest of this paper is organized as follows. We motivate technology risk within an ICAPM framework in Section 2 and construct the technology factor in Section 3. Sections 4 includes the testing strategy and main empirical results, and Section 5 describes relevant robustness checks. Section 6 summarizes this paper.

\section{Motivation}

Solow (1957) suggests that aggregate technology level should play an important role other than labor and capital in aggregate production function, which can be characterized as $Y_{t}=A_{t} F\left(n_{t}, k_{t}\right)$, 
where the total output $Y_{t}$ at time $t$ is determined by aggregate technology level $\left(A_{t}\right)$, labor input $\left(n_{t}\right)$, and capital input $\left(k_{t}\right)$. The main implication is that, even with fixed labor and capital input, an economy can still grow and fluctuate due to variant technology condition. When this argument is connected to the long-term budget constraint as well as permanent income hypothesis, the investors' optimal consumption should take account of the expectation of future technology level. When there happens good news to technology prospects, investors would anticipate a persistent increase in future output, thanks to technological progress. As a result, investors will have less restricted long-term budget constraints, which raise the consumption today (e.g. Campbell, 1993, 1994) because, unlike most other productivity shocks, technology shocks tend to have more persistent real effects on the economy.

By assuming a positive relation between aggregate consumption and technology prospects, we can develop an ICAPM with technology risk. We first let optimal consumption $c_{t}$ be an increasing function of technology prospects $z_{t}$ at time $t$. Note that $z_{t}$ is the expectation of future technological progress, not realized technological progress. Then, $c_{t}=C\left(z_{t}\right)$ with $\partial C\left(z_{t}\right) / \partial z_{t}>0$ and the SDF between time $t$ and $t+1, m_{t+1}$, can be derived as

$$
m_{t+1}=\beta \frac{u_{c}\left(c_{t+1}\right)}{u_{c}\left(c_{t}\right)}=\beta \frac{V_{w}\left(w_{t+1}, z_{t+1}\right)}{V_{w}\left(w_{t}, z_{t}\right)},
$$

where $u(\cdot)$ is the utility function, $w_{t}$ denotes the total wealth at time $t$, and $V(\cdot)$ denotes the value function in a Bellman equation. The equation holds as $V_{w}\left(w_{t}, z_{t}\right)=u_{c}\left(c_{t}\right)$. Then, based on the first-order Taylor approximation, we obtain a linear SDF

$$
m_{t+1}=\frac{\beta w_{t} V_{w w}\left(w_{t}, z_{t}\right)}{V_{w}\left(w_{t}, z_{t}\right)} \Delta w_{t+1}+\frac{\beta z_{t} V_{w z}\left(w_{t}, z_{t}\right)}{V_{w}\left(w_{t}, z_{t}\right)} \Delta z_{t+1}
$$

where $\Delta w_{t+1}=\left(w_{t+1}-w_{t}\right) / w_{t}$ as the market wealth growth and $\Delta z_{t+1}=\left(z_{t+1}-z_{t}\right) / z_{t}$ as the changes (news) in technology prospects. The above derivations clearly show that the changes in technology prospects enter into the SDF as a systematic risk, i.e. technology risk, other than market risk. Moreover, for risk-averse investors, the factor loading $\beta z_{t} V_{w z}\left(w_{t}, z_{t}\right) / V_{w}\left(w_{t}, z_{t}\right)$ should be negative as $\partial C\left(z_{t}\right) / \partial z_{t}>0$. 
This proposition is consistent with the consumption risk literature. Campbell (1993) and Chen (2003) argue that, due to long-term aggregate budget constraints, news about the future prospects or volatility of the market wealth has to affect current consumption. Therefore, an economic state variable can earn a risk premium by conveying news regarding changes in the expectation of future market returns. In a broader scope, Bansal and Yaron (2004) show that time-varying prospects of long-run economic growth lead to long-run consumption risk and can explain many stylized features of asset returns.

Although so far our argument is based on consumption risk, we recognize that technology shocks could enter into asset pricing models more directly. For example, Cochrane (1991), Balvers and Huang (2007a), and Belo (2009) have demonstrated that the production side dynamics including productivity/technology shocks can enter into the pricing kernel without resorting to consumption dynamics. Their studies provide pure production-based motivations for this paper.

\section{A Return-based Technology Factor}

In this section, we construct a technology factor $\left(R^{\text {tech }}\right)$ that serves as an empirical proxy of the changes in technology prospects $(\Delta z)$ and allows us to inspect the influence of technology uncertainty on consumption and stock returns. This measurable, return-based factor is found distinct from conventional risk factors and positively correlated with consumption growth.

\subsection{The construction}

We use U.S. patent shocks proposed in Hsu (2009), available from 1977Q1 to 2007Q4, as the proxy of future technological innovations. This innovation measure gives us a larger sample size than most other technology measures. ${ }^{6}$ All data considered in our empirical analysis are on a

\footnotetext{
${ }^{6}$ In the Compustat database, firms' quarterly and annual R\&D expenses are available since 1989 and 1950 , respectively. Some other annual technology statistics, such as NSF R\&D data, are available back to the early 1950 s. Alexopoulos' (2006) new measure, based on numbers of books, is also available in annual frequency since 1955.
} 
quarterly basis. We employ Lamont's (2001) tracking portfolio approach, which enables us to measure the market's expectation of future technological innovations, i.e. technology prospects. We regress one-quarter ahead patent shocks $\left(T e c h_{t+1}\right)$ on current base assets' excess returns and lagged control variables using a 20-quarter window:

$$
\text { Tech }_{t+1}=a_{0, t}+a_{1, t} B_{t}+a_{2, t} C_{t-1}+\epsilon_{t+1},
$$

where $a_{0, t}$ is the intercept term, $a_{1, t}$ denotes a vector of coefficients (i.e. projection loadings or weights, for the excess returns of base assets $B_{t}$ ), and $a_{2, t}$ denotes a vector of coefficients for lagged control variables $C_{t-1}$. As suggested in Lamont (2001) and Vassalou (2003), we have to include control variables to "filter" known information, so as to measure the "news" related to future economic states. The residual term $\epsilon_{t+1}$ describes technological innovations irrelevant to financial markets. Then, we generate the technology factor as the series of base assets' excess returns multiplied by time-variant projection weights, i.e. $R_{t}^{t e c h}=a_{1, t} B_{t}$, which serves as a return-based technology factor tracking the changes in technology prospects. The positive $R_{t}^{\text {tech }}$ implies that technology prospects at time $t$ are brighter than the past period. In the following context, we will use the technology factor and $R^{\text {tech }}$ interchangeably.

Twelve base assets are considered: Six Fama-French portfolios (Fama and French, 1993), five industry portfolios, and the market portfolio, all available from Kenneth French's website. The first group is sorted by size and book-to-market value, and the second group includes Consumer, Manufacturing, High-tech, Health, and Others. The excess returns (in excess of one-month T-bill returns) of these base assets form $B_{t}$, which is a "zero-cost" portfolio at each period. Four control variables are considered: Term spread, default spread, cay by Lettau and Ludvigson (2001a), and the industrial production growth for the past year. ${ }^{7}$

Some facets of our empirical strategy are worth mentioning. First, the five-year window has

\footnotetext{
${ }^{7}$ Term spread is 10-year treasury constant maturity rate (GS10) minus 1-year treasury constant maturity rate (GS1) and default spread is Moody's Baa corporate bond rate minus Aaa corporate bond rate, all from Federal Reserve Economic Data (FRED). cay is from Martin Lettau's website. ndustrial production growthis the growth rate of the seasonally adjusted industrial production index (INDPRO), also from FRED.
} 
been widely adopted in the literature (e.g. Chen, Roll, and Ross, 1986; Chan, Karceski, and Lakonishok, 1998). Second, we use five industry portfolios other than Fama-French six portfolios because industry portfolios could be very sensitive to technology changes as they are sorted on production characteristics. Third, the rolling regression estimation is used to (1) avoid the lookingforward bias, (2) capture the time-varying dynamics between individual base assets and technology prospects because technological innovations are industry-specific and much more volatile than other macroeconomic variables, such as GDP, and (3) better measure the rise and fall among industries due to technological revolutions. Fourth, the control variables we use are selected from a group of variables used in Lamont (2001) and Vassalou (2003) as they perform predictive ability for the base assets' excess returns. Lastly, directly bringing patent shocks into the crosssectional testing is empirically feasible but may not be very efficient for two reasons: (1) The estimate of technology risk premium becomes hard to explain because technological innovations are not monetary; (2) as mentioned in the literature (e.g. Cochrane, 2001, p.167; Vassalou, 2003), economic variables that are not in return format could contain noises irrelevant to financial markets, which lower the power of the asset pricing test.

The time series of $R^{\text {tech }}$ is plotted in Figure 1, which shows three peaks: the first one in 1984, the second one in 1999, and the last one in 2002, reflecting the prevailing optimism in those years. Note that the sample period starts in 1981Q4 and ends in 2007Q3, as Tech in the first 20 quarters (1977Q1-1981Q4) are used to construct the first point of the technology factor (1981Q4). The shaded parts denote the NBER recession periods. It appears that the the business recession does not correlate with the technology factor, suggesting that the technology factor is not simply a proxy of business cycles. The time-variant projection loadings of base assets are provided in Figure 2. We observe that the loadings of big growth stock (BL), small value stock (SH), hi-tech stock, and the market portfolio are most volatile among twelve base assets. 


\subsection{Summary statistics and correlations}

Table 1 reports the summary statistics of $R^{\text {tech }}$, Tech, other systematic risk factors (MKT, SMB, HML, and UMD), and the consumption growth. ${ }^{8}$ The sample period for Tech starts in 1977Q1, and all other variables start in 1981Q4. The time series average of $R^{\text {tech }}$ is $0.51 \%$ per quarter with a $t$-statistic of 2.56 , indicating significant technology risk premia that deserve further examination. We also note that both $R^{\text {tech }}$ and Tech are autocorrelated, which are consistent with persistent technology shocks suggested in the macroeconomics literature. Panel B shows that the correlation between $R_{t}^{\text {tech }}$ and $T e c h_{t+1}$ amounts to $29.7 \%$ with $p$-value less than $1 \%$. Since we adopt a rolling approach to track the anticipation of future technology innovations, an almost $30 \%$ correlation coefficient is convincingly high. Pearson's correlation test indicates that $R^{\text {tech }}$ is not statistically correlated with other common risk factors (MKT, SMB, HML, and UMD) at 5\% level. In unreported tables, we regress $R^{\text {tech }}$ on these risk factors and find the estimate for the intercept remains in a similar magnitude of significance $(0.6 \%$ with $t$-statistic 2.51$)$. Therefore, it is fair for us to believe that the technology factor is a distinct risk factor, not simply a linear combination of existent ones. Panel B also indicates that the technology factor is strongly correlated with consumption growth $(25.4 \%$ with $p$-value around $1 \%)$.

In Panel $\mathrm{C}$ of the same table, we regress consumption growth and the long-term consumption growth, i.e. the growth of the consumption trend based on Hodrick and Prescott's (1997) method, on the technology factor and market returns. $R^{\text {tech }}$ is found to significantly explain contemporaneous consumption growth. The technology factor explains over $5 \%$ of consumption growth and $11.4 \%$ of long-term consumption growth. On the other hand, it is noteworthy that market returns have only limited explanatory power for long-term consumption growth. In unreported tables, we obtain similar results by including other risk factors or running conditional regressions with

\footnotetext{
${ }^{8}$ MKT, SMB, HML, and UMD are available from Kenneth French's website. MKT denotes the market premium (CRSP value-weighted return minus one-month T-bill return), SMB denotes the return spread between small stocks and big stocks (SMB), HML denotes the return spread between value stocks and growth stocks, and UMD denotes the return spread between high-momentum stocks and low-momentum stocks. The consumption growth is obtained from Martin Lettu's cay data set.
} 
instrumental variables. All these findings corroborate the ICAPM motivation: The changes in technology prospects affect consumption growth and marginal utility, and therefore could enter into the SDF as a systematic risk source.

\section{Empirical Testing}

\subsection{Testable hypotheses and testing methodology}

To empirically justify if the technology factor enters into the SDF, we employ Cochrane's (1996, 2001) procedure of cross-sectional testing. Based on Equation (2), we consider the following three linear SDF models:

$$
\begin{aligned}
& m_{t}=b_{0}+b_{m} M K T_{t}+b_{\text {tech }} R_{t}^{\text {tech }} \\
& m_{t}=b_{0}+b_{m} M K T_{t}+b_{s m b} S M B_{t}+b_{h m l} H M L_{t}+b_{t e c h} R_{t}^{t e c h} \\
& m_{t}=b_{0}+b_{m} M K T_{t}+b_{s m b} S M B_{t}+b_{h m l} H M L_{t}+b_{u m d} U M D_{t}+b_{t e c h} R_{t}^{\text {tech }},
\end{aligned}
$$

where $b_{0}$ is a free parameter, and $b_{m}, b_{s m b}, b_{h m l}, b_{u m d}$, and $b_{\text {tech }}$ are the loadings of MKT, SMB, HML, UMD, and $R^{\text {tech }}$, respectively. The risk premia associated with all factors including $\lambda_{m}$

for MKT, $\lambda_{s m b}$ for SMB, $\lambda_{h m l}$ for HML, $\lambda_{\text {umd }}$ for UMD, and $\lambda_{\text {tech }}$ for $R^{\text {tech }}$, can be derived accordingly.

Equation (4) is equivalent to Merton's ICAPM with the technology factor. Equation (5) extends the ICAPM by considering SMB and HML proposed by Fama and French (1993) based on Arbitrage Pricing Theory (APT) of Ross (1976). Equation (6) further includes UMD proposed by Carhart (1997) in the linear structure. When we remove the technology factor from the above three models, they represent the capital asset pricing model (CAPM), Fama-French three-factor (FF3) model (Fama and French, 1993), and Carhart four-factor model (FF3 plus UMD, Carhart, 1997), respectively. These three models serve as benchmark models in our testing. However, we shall use UMD in our analysis with caution, since the momentum effect exists in the covariance 
structure, and there is very little theoretical basis to justify the existence of such a factor in the SDF.

The linear factor setting allows us to examine and interpret the effect of technology risk in asset returns in a standard, straightforward way. Since our goal is to justify the existence of a new systematic risk, we prefer such a standard approach. The significance of $b_{\text {tech }}$ can be interpreted as the changes in technology prospects help to price assets, and the significance of $\lambda_{\text {tech }}$ indicates that the technology risk is priced in assets. As argued in the motivation section, we suspect negative $b_{\text {tech }}$ and positive $\lambda_{\text {tech }}$ because technology prospects are positively correlated with consumption growth.

Based on Equations (4) to (6), we set the pricing errors $g_{j}=E_{T}\left[m_{t+1} R_{j, t+1}^{e}\right]$ and search for $\hat{b}$ (a vector including all $b \mathrm{~s}$ in a SDF model) that minimizes the average of squared pricing errors. Following Cochrane (2001), we implement one stage Generalized Method of Moments (GMM) estimation because we focus on the economically more interesting combination of assets by giving the same weight to all testing assets. Multil-stage GMM estimation usually delivers a poorly estimated variance-covariance matrix when the cross section is large, which happens to be our case. Newey-West (1987a) lag is set to be the observation size to the power of one third. The GMM $t$-statistics for $b$ s are used for statistical inferences. The $t$-statistics for $\lambda$ s are inferred via delta method.

We recognize the potential bias of generated regressors, since we conduct the cross-sectional testing with a factor based on pre-specified tracking portfolios. The GMM standard errors we reported have not been corrected for that bias. One solution would be to use GMM to estimate the fixed weights of base assets and all SDF parameters simultaneously, such as Vassalou (2003). However, we prefer a rolling estimation approach for an empirical reason: we want to capture the time-varying dynamics between individual base assets and technology prospects, as some industries have higher technology loadings than others at some specific periods. Since dealing 
with the bias of generated regressors deviates from our empirical interest, we leave it to future research.

\subsection{Testing assets}

Our testing asset set is composed of the following 45 portfolios: FF25 portfolios, ten momentum portfolios, and ten R\&D portfolios ("FF35 plus R\&D10" hereafter). These testing assets are considered for three reasons: (1) We are mainly concerned about the connection between firms' technology-related characteristics and their stock returns; (2) technology risk may help to explain the momentum spread; ${ }^{9}$ and $(3)$ the introduction of new testing assets can relax the strong factor structure of FF25 portfolios mentioned by Lewellen, Nagel, and Shanken (2008) and Daniel and Titman (2006). We do consider other testing asset sets, such as FF25 portfolios, and obtain conceivably similar results reported in the robustness check section.

We construct ten R\&D portfolios by sorting all firms into ten groups based on R\&D intensity, which is defined as each firm's annual $R \& D$ expenses relative to its annual sales. At the end of each June from 1976 to 2007, we sort all non-financial stocks in the CRSP and Compustat data that report positive $R \& D$ expenditures into deciles based on $R \& D$ intensity. Then, we track the value-weighted returns of stocks in these deciles in the following four quarters as the returns of ten R\&D portfolios.

\subsection{Testing results}

Table 2 reports our main results. In Panel A, when we compare the ICAPM with the technology factor $(\sharp 1)$ to the CAPM $(\sharp 2)$, we find that the technology factor significantly helps pricing asset returns as $b_{\text {tech }}$ is found to be -49.56 with $t$-statistic -2.29 . Then, we find that technology risk is

\footnotetext{
${ }^{9}$ Since technological innovations consistently drive up production growth, they may explain the momentum phenomenon. Apedjinou and Vassalou (2004) find that corporate innovations can explain firm-level momentum phenomenon. Liu and Zhang (2008) show that the growth rate of industrial production is a risk factor and explains a large portion of the momentum phenomenon.
} 
significantly priced as the estimated risk premium $\lambda_{\text {tech }}$ is $2.11 \%$ per quarter with $t$-statistic 3.06 . The existence of the technology factor greatly improves the cross-sectional fitting of asset returns by increasing the R-square from $2.9 \%$ to $32.7 \%$. This magnitude suggests that, as a single factor, the technology factor explains about $30 \%$ of the cross-sectional variation of stock returns. This finding is formally confirmed with the result of the JT difference test (Newey and West, 1987b) in the rightmost column. It rejects the null hypothesis that the addition of the technology factor does not improve the explanation of asset returns. In Panel B, we add SMB, HML, and UMD into the SDF testing and estimate $b_{\text {tech }}$ and $\lambda_{\text {tech }}$ to be -31.75 and $1.22 \%$, with $t$-statistics -2.81 and 3.13 , respectively. While comparing the results in $\sharp 3$ to $\sharp 4$, we find that the technology factor still effectively improves the model fitting by increasing the R-square by almost $8 \%$ ( $50.3 \%$ to $58.1 \%$ ). The JT difference test also indicates such incremental improvement to be statistically substantial. As a result, the technology factor improves upon the performance of the CAPM and Fama-French three-factor model in pricing assets.

There are some more findings worth mentioning. First, we note that the estimated technology $\lambda \mathrm{s}$ are larger than the time series average of the technology factor reported in Table 1 . This finding is driven by the composition of base assets. Since we include Fama-French six portfolios in the base assets in constructing the technology factor, testing the technology factor using FF25 portfolios may result in inflated risk price of the technology factor. Lower price of technology risk is obtained when we use other testing assets in the robustness check section. Second, we note that all loadings and risk premia of MKT and SMB are insignificant in Table 2. This observation is consistent with the literature that the market factor can not price FF25 portfolios, and the size effect is disappearing in most recent decades. Third, the HML marginally helps to price assets but its premium is not significant. Fourth, the JT test (Hansen, 1982) rejects all models in this table. The rejection of JT tests indicates a lack of fit in an over-identification procedure, which is commonly observed in unconditional cross-sectional tests (e.g. Vassalou, 2003; Balvers and 
Huang, 2007a). Later, we will consider a conditional test that alleviates this issue.

Figure 3 illustrates the advantage of considering the technology factor in the cross-sectional prediction. In the upper left panel, we find that, without the technology factor and the UMD, the distribution of all returns looks almost like a horizontal line, indicating a poor fitting. On the upper right panel, we observe the ICAPM with the technology factor shows an upward trend with R-square of $32.7 \%$. Even at the presence of the UMD, we still find that the existence of the technology factor helps the cross-sectional fitting, as shown in the two lower panels.

In Figure 4, we plot the time series of two SDFs. The blue line is based on FF3 plus UMD, and the red line is based on FF3 plus UMD and Tech. The vertical difference between these two lines can be regarded as the impact of technology prospects. We observe that the major impacts of technology prospects coincide with the internet bubble. The red line spikes in 1997, and then plummets in 1999. The deep drop of the SDF during 1997-1999 reflects the market's over-optimism in technology prospects and the prevailing impatience. The slump also suggests the rising expected returns on all assets, which is consistent with the surge of stock markets in that period. Since 1999, the SDF pulls back to another peak in 2001, which suggests that dimming technology prospects cause investors to be more cautious, consistent with the market crash in that period.

We then inspect testing assets' exposure to technology risk in Table 3, which reports each testing asset's technology betas and corresponding Newey-West (1987a) $t$-statistics in the ICAPM and FF3 plus UMD and $R^{\text {tech }}$. To simplify the description, we focus on Panel A, which is based on the ICAPM. Among FF25 portfolios, we find that small and growth firms carry positive technology betas, while big and value firms carry negative technology betas. This finding suggests that the returns of small growth stocks are more sensitive to the changes of technology prospects, which is intuitive as the demand of small growth stocks should depend on the technology prospects to a larger degree. On the other hand, the negative technology betas occurring in big value stocks 
may look somewhat puzzling, but could be attributed to the hedge demand. Since firms in this category are financially solid and have deep pockets for technology investment, investors can use these stocks as vehicles to hedge against technology risk.

The technology betas of momentum portfolios and R\&D portfolios are discussed together. Among ten momentum portfolios, we note that the highest momentum portfolio carries positive technology beta (0.593) and all five low momentum portfolios carry negative technology betas. This observation agrees with our earlier finding that the technology factor seems to explain a part of the momentum phenomenon. One explanation is that the industry-specific momentum (Moskowitz and Grinblatt, 1999) occurs as technology prospects may create momentums within different industries to various extents. Among ten R\&D portfolios, we find that the highest R\&Dintensive portfolio carries the highest technology beta (2.03) and lower R\&D-intensive portfolios carry negative technology betas. These two findings coincide as each firm's R\&D intensity (or technology sensitivity) is a persistent characteristic.

The rightmost column of the same table reports the results of two $F$-tests. The first one inspects if all technology betas are jointly significant (from zero) following Petkova (2006), and the second one examines if all technology betas are the same. Both tests strongly reject the null hypotheses and suggest various exposures of different assets to technology risk. We recognize that only a few technology betas deliver extremely high or low $t$-statistics. Since the proposed technology factor is motivated by aggregate consumption growth instead of statistical arbitrage, it does not have to significantly explain the time series variation of each asset's return series (e.g. Lettau and Ludvigson, 2001b; Balvers and Huang, 2007a). As mentioned in Cochrane (p. 183, 2001), the factor pricing (i.e. $m=b f$ ) does not require a factor structure $(r=a+\beta f$ ) and strong covariance among returns. Moreover, since Table 3 reports the estimates only based on the whole sample period, it does not fully reveal each portfolio's time-varying risk exposure to technology risk. 


\subsection{Conditional tests}

We then consider a conditional test based on the "scaled factor" approach proposed by Cochrane (1996). We assume that the factor $j$ 's $b_{j}$ is now time-varying in a format $b_{j, t}=b_{j, 0}+\sum_{i=1, \ldots, I} b_{j, i} Z_{i, t}$, where $Z_{i, t}$ denotes an instrumental variable $i$ at time $t$. We aim to test if the unconditional technology risk loading $b_{\text {tech }, 0}$ and premium $\lambda_{\text {tech }, 0}$ are significant and if any other instrumental variable $i$ significantly affects the technology loading, i.e. $b_{\text {tech }, i} \neq 0$. The three instrumental variables we consider are term spread, cay, and one-year industrial production growth. We find that the unconditional technology loading and premium remain significant and the instrumental variables affect only the price of technology risk. In Panel A of Table 4, we consider a conditional ICAPM with the technology factor and find that the unconditional technology risk loading $b_{\text {tech }, 0}$ and premium $\lambda_{\text {tech }, 0}$ are estimated to be -107.87 and $2.35 \%$, with $t$-statistics -2.82 and 3.05 , respectively. The R-square of $\sharp 1$ is as high as $53.9 \%$, while the R-square of $\sharp 2$ is only $11.0 \%$. Note that the difference in R-square between the ICAPM and CAPM model amounts to $42.9 \%$, which is much larger than the R-square difference of $29.8 \%$ in Table 2. Such a gap suggests that accounting for conditional information further strengthens the explanatory power of the technology factor. We also note that, unlike $\sharp 2$, the JT test does not reject the SDF model in $\sharp 1$. This finding justifies the empirical success of the proposed ICAPM with the technology factor.

In Panel B, we add three other factors (SMB, HML, and UMD) and associated scaled factors, and find very similar, albeit weaker, results. The unconditional technology risk loading $b_{\text {tech }, 0}$ and premium $\lambda_{\text {tech, } 0}$ are estimated to be -90.85 and $1.45 \%$, with $t$-statistics -1.72 and 2.49 , respectively. The existence of the technology factor and associated scaled factors increase Rsquare from $85.2 \%$ to $92.0 \%$, which is commensurate to the improvement in Panel B of Table 2. Overall, our results so far strongly support the claim that the technology factor plays a substantial role in asset pricing models and significantly helps to price stock returns. 


\subsection{Comparison with consumption growth and cay}

In Table 5, we compare the technology factor to the three consumption factors proposed in Lettau and Ludvigson (2001b). We find that, when cay, consumption growth $(\Delta C)$, and their interaction term $(\Delta C \cdot$ cay $)$ appear in the linear SDF model, the technology factor's loading and premium remains significant. Panel A shows that, without the technology factor, the market factor and three consumption factors explain only $22.0 \%$ of the cross-sectional variation. When the technology factor is included in the SDF, 36.1\% of stock returns can be explained. The JT difference test supports such substantial improvement. Moreover, the $t$-statistics for $b_{\text {tech }}$ and $\lambda_{\text {tech }}$ are -1.86 and 2.73, respectively. Panel B reports that, when three other factors (SMB, HML, and UMD) are considered in the SDF, the technology factor is still priced and helps to price the assets, as the $t$-statistics for $b_{\text {tech }}$ and $\lambda_{\text {tech }}$ are -2.93 and 2.86 , respectively. We also notice that the estimates of $b_{\text {tech }}$ and $\lambda_{\text {tech }}$ in Table 5 are commensurate to those in Table 2. So, although $R^{\text {tech }}$ is a consumption-motivated factor, it is able to provide extra information beyond conventional consumption factors.

\section{Robustness checks}

For the first robustness check, we test the SDF model using FF25 portfolios only. Table 6 shows that, when we test the ICAPM with the technology factor in pricing FF25 portfolios $(\sharp 1)$, we find that $R^{\text {tech }}$ delivers (marginally) significant $b_{\text {tech }}$ and $\lambda_{\text {tech }}$ with R-square $47.6 \%$. In comparison with the CAPM $(\sharp 2)$, the technology factor increases R-square by $12.5 \%$, rejecting the JT difference test. Then, we consider SMB and HML in testing model $\sharp 3$ and observe that the technology risk loading $b_{\text {tech }}$ becomes insignificant and the technology premium $\lambda_{\text {tech }}$ becomes only marginally significant. Nevertheless, they remain the right signs. On the other hand, the Fama-French threefactor model provides $67.6 \%$ R-square in $\sharp 4$. Although this table shows the underperformance of the technology ICAPM against Fama-French three-factor model, it is noteworthy that the 
technology ICAPM performs remarkably well in explaining the return spread from size and bookto-market effects with R-square close to $50 \%$.

Next, we test the technology factor with 25 portfolios sorted on market betas and technology betas. At the end of each second quarter, we regress each stock's excess returns on MKT and one-quarter ahead patent shocks (Tech) over the past five years. Then, we assign all stocks into five-by-five squared quintiles based on their market betas and technology betas (separately). Lastly, the value-weighted returns of these 25 portfolios form the test portfolios. As reported in Table 7 , we find that $R^{\text {tech }}$ significantly helps pricing asset returns as $b_{\text {tech }}=-16.53$ with $t$-statistic -2.18 , and the technology risk is priced as $0.7 \%$ per quarter with $t$-statistic 1.82 . When we compare $\sharp 1$ to $\sharp 2$, we note that the existence of the technology factor increases the R-square from $2.7 \%$ to $28.5 \%$. Similar results are found when the other three factors are included in the SDF model. Note that our design is not an APT experiment as the technology factor is not formed on the return spread of the attribute portfolios, so a very high R-square is not granted.

We also consider a longer sample period back to 1963 by anchoring portfolio weights. We estimate the average weights of all base assets using the whole sample period 1977Q1-2007Q3, and then use those weights for all periods before 1981Q4. As reported in Table 8, the technology factor is of marginal significance in pricing assets and being priced in both test asset sets (FF35 plus R\&D10 and FF25). Moreover, the JT difference tests suggest that the existence of the extended technology factor significantly helps to improve the asset pricing model. We note that the effect of the technology factor is not as strong as in more recent sample periods (Table 2), which may be attributed to two reasons: First, the patent data could be a less precise proxy for aggregate technological development prior to the 1980s for historical reasons. According to Hall (2004), firms became more active in filing patents for their technological innovations since the establishment of a patent-specialized court (the Court of Appeals for the Federal Circuit, CAFC) in 1982 and a few highly publicized patent infringement cases in the mid-1980s. Second, 
the U.S. economy has experienced some radical changes in technologies and industries since the 1980s. Thus, using fixed loadings or fixed industry portfolios may not be the most effective way to capture technology risk.

In a recent study, Chen and Zhang (2009) find that stocks with different production characteristics, such as investment intensity and profitability, provide different returns. They argue that such a cross-sectional variation is due to the changes in productivity and investment cost. Since technological innovations are an important determinant of future productivity and investment opportunity, the technology factor may be able to explain their finding to a certain extent. We test the SDF models in ten investment-to-asset portfolios and ten profitability portfolios (separately) in Table 9. Testing these two classes separately helps us better understand the relation between technology prospects and the productivity effect or the investment effect. In Panel A of Table 9, we find that the technology factor helps to price ten investment-to-asset portfolios with statistical significance. The loading and unit risk price of the technology factor are -60.10 and $1.50 \%$, with $t$-statistics -2.06 and 2.25 , respectively. This finding is intuitive as it reflects that a (major) part of time-varying investment opportunities is driven by technological innovations. In Panel B, we find that the technology factor does not help to price ten profitability portfolios. This finding could be due to the formation methodology of these portfolios. They are sorted on past profitability, so do not necessarily reflect the future prospects of firms adopting new technologies.

We conduct the cross-sectional testing using a different set of testing assets including ten industry portfolios and the market portfolio. As reported in Table 10, the ICAPM with the technology factor in the pricing model $(\sharp 1)$ delivers significant $b_{\text {tech }}$ and $\lambda_{\text {tech }}$ with R-square $25.0 \%$. In comparison with the CAPM $(\sharp 2)$, the technology factor largely increases R-square by $22.1 \%$ and rejects the JT difference test. The significant existence of technology risk remains even when SMB, HML, and UMD are included in the testing model $(\sharp 3)$. Thus, our findings are reasonably robust to the specification of base assets. 
Lastly, we test the SDF model using all individual stocks as suggested in Ang, Liu, and Schwarz (2008). We implement the two-pass procedure of Fama and MacBeth (1973) with all available returns of individual stocks in the CRSP data set, and obtain the estimates of the price of risk associated with the technology factor to be $0.07 \%$ with $t$-statistic 2.10 in ICAPM, and $0.04 \%$ with $t$-statistic 1.56 in Carhart four-factor model plus the technology factor. We suspect that these relatively insignificant findings could be attributed to power and sensitivity issues. Using all individual stocks as testing assets aims to improve efficiency, not power. In addition, we are not sure if the majority of individual stocks carry substantial technology risk loadings. The earlier argument about technology betas may apply here as well.

\section{Concluding remarks}

Fluctuating technological progress is a determinant of future productivity and aggregate wealth. In an intertemporal economy, optimal consumption should be positively related with technology prospects, as better future technologies imply higher productivity and permanent income. Using a standard ICAPM framework, we argue that the changes in technology prospects work as a systematic risk factor in the pricing kernel and, thus, affect asset prices. This proposition is supported by our empirical study based on U.S. data of patents and stocks. We use tracking portfolios to project future technological innovations into current asset returns to form a tradable factor as a proxy of the changes in technology prospects. Consistent with the motivation, this factor positively correlates with consumption growth. Moreover, it effectively helps to explain the pricing models and is significantly priced. Lastly, the technology factor also explains the variation in stock returns driven by momentum, $R \& D$ intensity, and investment intensity to a certain extent. 


\section{References}

Alexopoulos, Michelle (2006) "Read all about it!! What happens following a technology shock?" working paper, University of Toronto.

Ang, Andrew, Robert Hodrick, Yuhang Xing, and Xiaoyan Zhang (2006) "The cross-section of volatility and expected returns," Journal of Finance, 61, 259-299.

Ang, Andrew, Jun Liu, and Krista Schwarz (2008) "Using stocks or portfolios in tests of factor models," working paper, Columbia University.

Apedjinou, Kodjo and Maria Vassalou (2004) "Corporate innovation, price momentum, and equity returns," working paper, Columbia University.

Balvers, Ronald J. and Dayong Huang (2007a) "Productivity-based asset pricing: Theory and evidence," Journal of Financial Economics, 86, 405-445.

Balvers, Ronald J. and Dayong Huang (2007b) "Money and the (C-)CAPM: Theory and evaluation," forthcoming, Journal of Financial and Quantitative Analysis.

Bansal, Ravi and Amir Yaron (2004) "Risks for the long run: A potential resolution of asset pricing puzzles," Journal of Finance, 59, 1481-1509.

Basu, Susanto and John Fernald (2002) "Aggregate productivity and aggregate technology," European Economic Review, 46, 963-991.

Belo, Frederico (2009) "A pure production-based asset pricing model," working paper, University of Minnesota.

Campbell, John Y. (1993) "Intertemporal asset pricing without consumption data," American Economic Review, 83, 487-512.

Campbell, John Y. (1994) "Inspecting the mechanism: An analytical approach to the stochastic growth model," Journal of Monetary Economics, 33, 463-506.

Carhart, Mark M. (1997) "On persistence in mutual fund performance," Journal of Finance, 52, $57-82$.

Chan, Louis K. C., Jason Karceski, and Josef Lakonishok (1998) "The risk and return from factors," Journal of Financial and Quantitative Analysis, 33, 159-188.

Chan, Louis K. C., Josef Lakonishok, and Theodore Sougiannis (2001) "The stock market valuation of research and development expenditures," Journal of Finance, 56, 2431-2456.

Chen, Joseph (2003), "Intertemporal CAPM and the cross-section of stock returns," working paper, University of California, Davis.

Chen, Long and Lu Zhang (2009) "A better three-factor model that explains more anomalies," forthcoming, Journal of Finance.

Chen, Nai-Fu, Richard Roll, and Stephen A. Ross (1986) "Economic forces and the stock market," Journal of Business, 59, 383-403. 
Chen, Nai-Fu (1991), "Financial investment opportunities and the macroeconomy," Journal of Finance, 46, 529-554.

Cochrane, John H. (1991) "Production-based asset pricing and the link between stock returns and economic fluctuations," Journal of Finance, 46, 209-237.

Cochrane, John H. (1996) "A cross-sectional test of an investment-based asset pricing model," Journal of Political Economy, 104, 572-620.

Cochrane, John H. (2001) Asset Pricing, Princeton University Press.

Daniel, Kent and Sheridan Titman (2006) "Market reactions to tangible and intangible information," Journal of Finance 61, 1605-1643.

Eberhart, Allan, William Maxwell, and Akhtar Siddique (2004) "An examination of long-term abnormal stock returns and operating performance following R\&D increases," Journal of Finance, 59, 623-650.

Fama, Eugene and James MacBeth (1973) "Risk, return, and equilibrium: Empirical tests," Journal of Political Economy, 71, 607-636.

Fama, Eugene and Kenneth French (1993) "Common risk factors in the returns on stocks and bonds," Journal of Financial Economics, 33, 3-56.

Friedman, Milton (1957) A Theory of the Consumption Function, Princeton: Princeton University Press.

Gala, Vito (2006) "Investment and returns," working paper, London Business School.

Gomes, Joao, Leonid Kogan, and Lu Zhang (2003) "Equilibrium cross section of returns," Journal of Political Economy, 111, 693-732.

Guo, Hui, Robert Savickas, Zijun Wang, and Jian Yang (2007) "Is value premium a proxy for time-varying investment opportunities: Some time series evidence," forthcoming, Journal of Financial and Quantitative Analysis.

Hall, Bronwyn (2004) "Exploring the patent explosion," Journal of Technology Transfer, 30, 35-48.

Hansen, Lars Peter (1982) "Large sample properties of generalized method of moments estimators," Econometrica, 50, 1029-1054.

Hodrick, Robert and Edward C. Prescott (1997) "Postwar U.S. business cycles: An empirical investigation," Journal of Money, Credit, and Banking, 29, 1-16.

Hsu, Po-Hsuan (2009) "Aggregate technology shocks, market returns, and market premiums," forthcoming, Journal of Financial Economics.

Jegadeesh, Narasimhan and Sheridan Titman (1993) "Returns to buying winners and selling losers: Implications for stock market efficiency," Journal of Finance, 48, 65-91.

Kaltenbrunner, Georg and Lars A. Lochstoer (2008) "Long-run risk through consumption smoothing," working paper, Columbia University. 
Lamont, Owen (2001) "Economic tracking portfolios," Journal of Econometrics, 105, 161-184.

Lettau, Martin and Sydney Ludvigson (2001a) "Consumption, aggregate wealth and expected stock returns," Journal of Finance, 51, 815-849.

Lettau, Martin and Sydney Ludvigson (2001b) "Resurrecting the (C)CAPM: A cross-sectional test when risk premia are time-varying," Journal of Political Economy, 109, 6, 1238-1287.

Lettau, Martin (2003) "Inspecting the mechanism: Closed-form solution for asset prices in real business cycle model," Economic Journal, 113, 550-575.

Lev, Baruch, and Theodore Sougiannis (1996) "The capitalization, amortization, and valuerelevance of R\&D," Journal of Accounting and Economics, 21, 107-138.

Lewellen, Jonathan, Stefan Nagel, and Jay Shanken (2008) "A skeptical appraisal of asset-pricing tests," forthcoming, Journal of Financial Economics.

Li, Dongmei (2007) "Financial constraints, R\&D investment, and stock returns," working paper, University of California - San Diego.

Liu, Laura Xiaolei and Lu Zhang (2008) "Momentum profits, factor pricing, and macroeconomic risk," Review of Financial Studies, 21, 2417-2448.

Merton, Robert C. (1973) "An intertemporal capital asset pricing model," Econometrica, 41, 867-887.

Moskowitz, Tobias J. and Mark Grinblatt (1999) "Do industries explain momentum?" Journal of Finance, 54, 1249-1290.

Newey, Whitney K. and Kenneth D. West (1987a) "A simple, positive semi-positive, heteroskedasticity and autocorrelation consistent covariance matrix," Econometrica, 55, 703-708.

Newey, Whitney K. and Kenneth D. West (1987b) "Hypothesis testing with efficient method of moments," International Economic Review, 28, 777-787.

Pakes, Ariel (1985) "On patents, R\&D, and the stock market rates of returns," Journal of Political Economy, 93, 390-409.

Panageas, Stavros and Jianfeng Yu (2006) "Technological growth, asset pricing, and consumption risk," working paper, University of Pennsylvania.

Papanikolaou, Dimitris (2008) "Investment-specific technological change and asset prices," working paper, Northwestern University.

Pastor, Lubos and Pietro Veronesi (2008) "Technological revolutions and stock prices," American Economic Review, forthcoming.

Petkova, Ralitsa (2006) "Do the Fama-French factors proxy for innovations in predictive variables?" Journal of Finance, 61, 581-612.

Ross, Stephen A. (1976) "The arbitrage pricing theory of capital asset pricing," Journal of Economic Theory, 13, 341-360. 
Solow, Robert M. (1957) "Technical change and the aggregate production function," Review of Economics and Statistics, 39, 312-320.

Vassalou, Maria (2003) "News related to future GDP growth as a risk factor in equity returns," Journal of Financial Economics, 68, 47-73.

Zhang, Lu (2005) "The value premium," Journal of Finance, 60, 67-103. 
Table 1. Basic statistics

Panel A reports the descriptive statistics of all variables, and Panel B reports the correlation between the technology factor $\left(R^{\text {tech }}\right)$ and other variables at time $t$ (patent shocks at time $t+1$ ). Sample periods include 1977Q1-2007Q4 for patent shocks (Tech), and 1981Q4-2007Q3 for all the others (because we need 20 quarters to construct the technology factor). $t$ statistic is used to test whether the means of considered variables are different from zero. "Con" denotes the simple consumption growth from Lettu's cay dataset. In Panel B, we inspect the pariwise correlation between all variables and report Pearson's $p$-values in parentheses. In Panel C, we regress consumption growth on a constant term, market return (MKT), and the technology factor. We consider two definitions of consumption growth: the simple growth and the trend growth based on the Hodrick-Prescott (1997) filter, and the latter is used to capture the long-term consumption changes without temporary noises. Numbers in parentheses are the $t$-statistics based on the Newey-West's estimator (1987), based on four lags.

\section{Panel A: Descriptive statistics}

\begin{tabular}{cccccccc} 
& \multicolumn{1}{l}{ tech } & Tech & MKT & SMB & HML & UMD & \multicolumn{1}{c}{ Con } \\
\hline Mean & $0.51 \%$ & $12.38 \%$ & $2.02 \%$ & $0.40 \%$ & $0.93 \%$ & $2.36 \%$ & $0.47 \%$ \\
Median & $0.37 \%$ & $-0.19 \%$ & $3.13 \%$ & $0.02 \%$ & $0.80 \%$ & $2.01 \%$ & $0.44 \%$ \\
Max & 0.067 & 3.039 & 0.206 & 0.191 & 0.206 & 0.260 & 0.012 \\
Min & -0.059 & -2.425 & -0.243 & -0.108 & -0.320 & -0.201 & -0.007 \\
Std. dev. & 0.020 & 1.027 & 0.083 & 0.053 & 0.067 & 0.071 & 0.003 \\
$t$ statistic & 2.562 & 1.229 & 2.487 & 0.772 & 1.425 & 3.399 & 14.362 \\
$\begin{array}{c}\text { Autocorr. } \\
\left(1^{\text {st }} \text { order }\right.\end{array}$ & 0.566 & 0.589 & -0.054 & 0.011 & 0.190 & 0.027 & 0.350
\end{tabular}

\section{Panel B: Correlations}

\begin{tabular}{|c|c|c|c|c|c|c|c|}
\hline & $R^{\text {tech }}$ & Tech & MKT & SMB & HML & UMD & Con \\
\hline \multirow[t]{2}{*}{$R^{\text {tech }}$} & & 0.297 & -0.101 & 0.062 & -0.156 & 0.179 & 0.254 \\
\hline & & $(0.002)$ & $(0.307)$ & $(0.532)$ & $(0.111)$ & $(0.068)$ & $(0.012)$ \\
\hline
\end{tabular}

\section{Panel C: Consumption and technology prospects}

\begin{tabular}{rrrrr} 
Consumption & Const. & $R^{\text {tech }}$ & MKT & Adj. $\mathrm{R}^{2}$ \\
\hline Simple growth & 0.004 & 0.042 & 0.004 & 0.050 \\
& $(10.78)$ & $(2.84)$ & $(0.85)$ & \\
HP-trend growth & 0.005 & 0.022 & 0.002 & 0.114 \\
& $(18.47)$ & $(2.56)$ & $(1.30)$ & \\
\hline
\end{tabular}


Table 2. Testing results: FF25, momentum 10, and R\&D10

This table reports the testing results of Cochrane's procedure based on the GMM $t$-statistics. The testing assets considered include FF 25 portfolios, ten momentum portfolios, and ten R\&D portfolios. In Panel A, we test the SDF model that includes MKT and $R^{\text {tech }}$. In Panel B, we test the SDF model that includes FF3, UMD, and $R^{\text {tech }}$. t-statistics are reported in parentheses. We conduct the JT test to examine if the SDF model is rejected, and the JT difference test to examine if the existence of $R^{\text {tech }}$ improves the explanation of stock returns. Sample period: 1981Q4-2007Q3.

\begin{tabular}{|c|c|c|c|c|c|c|c|c|c|c|}
\hline \multicolumn{2}{|l|}{ \# } & Constant & MKT & SMB & HML & UMD & $R^{\text {tech }}$ & $\mathrm{R}^{2}$ & JT test & JT diff \\
\hline \multicolumn{11}{|c|}{ Panel A } \\
\hline \multirow[t]{4}{*}{1} & $b$ & 1.118 & 3.698 & & & & -49.557 & $32.7 \%$ & 87.12 & 105.65 \\
\hline & $t$-stat $(b)$ & $(6.50)$ & $(1.32)$ & & & & $(-2.29)$ & & $(0.001)$ & $(0.000)$ \\
\hline & $\lambda(\%)$ & 5.989 & -3.397 & & & & 2.112 & & & \\
\hline & $t$-stat $(\lambda)$ & $(3.61)$ & $(-2.15)$ & & & & $(3.06)$ & & & \\
\hline \multirow[t]{4}{*}{2} & $b$ & 0.956 & 0.684 & & & & & $2.9 \%$ & 196.20 & \\
\hline & $t$-stat $(b)$ & $(17.25)$ & $(0.32)$ & & & & & & $(0.000)$ & \\
\hline & $\lambda(\%)$ & 2.864 & -0.495 & & & & & & & \\
\hline & $t$-stat $(\lambda)$ & $(2.20)$ & $(-0.36)$ & & & & & & & \\
\hline \multicolumn{11}{|c|}{ Panel B } \\
\hline \multirow[t]{4}{*}{3} & $b$ & 1.330 & -1.036 & -1.284 & -4.975 & -5.434 & -31.747 & $58.1 \%$ & 114.08 & 37.39 \\
\hline & $t$-stat (b) & (6.96) & $(-0.32)$ & $(-0.40)$ & $(-1.63)$ & $(-0.21)$ & $(-2.81)$ & & $(0.000)$ & $(0.000)$ \\
\hline & $\lambda(\%)$ & 2.641 & -0.285 & 0.026 & 1.062 & 2.145 & 1.222 & & & \\
\hline & $t$-stat $(\lambda)$ & $(2.51)$ & $(-0.23)$ & $(0.05)$ & $(1.58)$ & $(3.04)$ & $(3.13)$ & & & \\
\hline \multirow[t]{4}{*}{4} & $b$ & 1.235 & -1.696 & -2.709 & -4.582 & -7.092 & & $50.3 \%$ & 140.08 & \\
\hline & $t$-stat (b) & (8.99) & $(-0.63)$ & $(-0.92)$ & $(-1.82)$ & $(-3.38)$ & & & $(0.000)$ & \\
\hline & $\lambda(\%)$ & 1.093 & 1.175 & 0.122 & 0.778 & 2.019 & & & & \\
\hline & $t$-stat $(\lambda)$ & $(0.97)$ & $(0.87)$ & $(0.24)$ & (1.04) & $(2.88)$ & & & & \\
\hline
\end{tabular}


Table 3. Technology betas of testing assets: FF35 plus R\&D10

We run time series regressions by regressing each testing asset's (FF25, ten momentum, and ten R\&D portfolios) excess returns on pre-specified risk factors, and report their technology betas (technology risk loadings) in this table. In Panel A, the risk factors we consider include MKT and $R^{\text {tech }}$. In Panel B, the risk factors we consider include FF3, UMD, and $R^{\text {tech }} . t$-statistics are computed based on the Newey-West's estimator to four lags. The $F$-statistics indicate the joint significance of technology betas in an SUR system ( 1 for all zero technology betas and 2 for the equality of all technology betas).

\begin{tabular}{|c|c|c|c|c|c|c|c|c|c|c|c|c|c|c|}
\hline \multirow{2}{*}{$\begin{array}{c}\text { Panel A } \\
\text { FF25 }\end{array}$} & \multicolumn{6}{|c|}{ Technology betas } & \multicolumn{6}{|c|}{$t$-statistics of technology betas } & \multirow{2}{*}{$\begin{array}{r}F \text {-stat } 1 \\
2.074\end{array}$} & \multirow{2}{*}{$\begin{array}{r}F \text {-stat 2 } \\
82.33\end{array}$} \\
\hline & & Small & 2 & 3 & 4 & $\overline{B i g}$ & & Small & 2 & 3 & 4 & Big & & \\
\hline & Growth & 0.641 & 0.137 & 0.144 & 0.512 & -0.185 & Growth & 0.94 & 0.41 & 0.57 & 1.19 & -1.33 & $(0.00)$ & $(0.00)$ \\
\hline & 2 & 0.442 & 0.068 & 0.139 & -0.135 & -0.251 & 2 & 1.01 & 0.24 & 0.63 & -0.46 & -1.40 & & \\
\hline & 3 & 0.326 & -0.036 & -0.270 & -0.170 & -0.109 & 3 & 1.00 & -0.11 & -0.82 & -0.59 & -0.53 & & \\
\hline & 4 & 0.106 & -0.317 & -0.431 & -0.268 & -0.549 & 4 & 0.30 & -0.74 & -1.07 & -1.13 & -1.64 & & \\
\hline & Value & 0.130 & -0.099 & -0.318 & -0.161 & -0.703 & Value & 0.31 & -0.22 & -0.87 & -0.47 & -1.75 & & \\
\hline \multirow[t]{2}{*}{ Momentum } & Low to 5 & -0.094 & -0.140 & -0.468 & -0.492 & -0.436 & Low to 5 & -0.20 & -0.46 & -1.23 & -1.33 & -1.61 & & \\
\hline & 6 to High & -0.205 & -0.218 & -0.206 & -0.158 & 0.593 & 6 to High & -0.87 & -0.83 & -1.82 & -0.86 & 1.65 & & \\
\hline \multirow[t]{2}{*}{$\mathrm{R} \& \mathrm{D}$} & Low to 5 & 0.076 & -0.663 & -0.152 & -0.086 & 0.220 & Low to 5 & 0.53 & -2.12 & -0.58 & -0.41 & 0.96 & & \\
\hline & 6 to High & -0.142 & 0.009 & 0.577 & 0.900 & 2.030 & 6 to High & -0.57 & 0.02 & 0.80 & 1.40 & 1.34 & & \\
\hline Panel B & \multicolumn{6}{|c|}{ Technology betas } & \multicolumn{6}{|c|}{$t$-statistics of technology betas } & $F$-stat 1 & $F$-stat 2 \\
\hline \multirow[t]{6}{*}{ FF25 } & & Small & 2 & 3 & 4 & Big & & Small & 2 & 3 & 4 & Big & 2.314 & 99.25 \\
\hline & Growth & 0.033 & -0.250 & -0.244 & 0.164 & -0.231 & Growth & 0.10 & -1.95 & -1.86 & 0.89 & -3.45 & $(0.00)$ & $(0.00)$ \\
\hline & 2 & 0.048 & -0.136 & 0.027 & -0.104 & -0.118 & 2 & 0.23 & -1.16 & 0.19 & -0.69 & -1.02 & & \\
\hline & 3 & 0.001 & -0.125 & -0.216 & -0.079 & 0.095 & 3 & 0.01 & -1.15 & -1.88 & -1.00 & 0.75 & & \\
\hline & 4 & -0.196 & -0.317 & -0.303 & -0.134 & -0.276 & 4 & -1.75 & -1.97 & -2.25 & -0.99 & -2.74 & & \\
\hline & Value & -0.049 & -0.034 & -0.158 & 0.040 & -0.299 & Value & -0.39 & -0.40 & -1.12 & 0.23 & -1.53 & & \\
\hline \multirow[t]{2}{*}{ Momentum } & Low to 5 & 0.210 & 0.143 & -0.181 & -0.226 & -0.271 & Low to 5 & 1.07 & 1.25 & -1.08 & -1.39 & -1.81 & & \\
\hline & 6 to High & -0.158 & -0.174 & -0.277 & -0.311 & 0.063 & 6 to High & -0.96 & -1.11 & -2.50 & -1.96 & 0.51 & & \\
\hline \multirow[t]{2}{*}{$\mathrm{R} \& \mathrm{D}$} & Low to 5 & 0.225 & -0.400 & -0.089 & 0.017 & 0.219 & Low to 5 & 1.29 & -1.90 & -0.58 & 0.11 & 1.35 & & \\
\hline & 6 to High & -0.185 & -0.079 & 0.216 & 0.552 & 1.241 & 6 to High & -0.95 & -0.36 & 0.57 & 1.32 & 1.46 & & \\
\hline
\end{tabular}


Table 4. Testing results conditioning on instrumental variables

This table reports the testing results of Cochrane's procedure based on the GMM $t$-statistics. The testing assets considered include FF 25 portfolios, ten momentum portfolios, and ten R\&D portfolios. In Panel A, we consider a linear SDF model based on scaling factors, as all linear combinations between one risk factor (FF3, UMD, and $R^{\text {tech }}$ ) and one instrumental variable (10-year to 1-year T-bond term spread, one year industrial production growth, or cay). Moreover, the intercept term and three instrumental variables are also considered in the model. Due to the large size of parameters, we only report selected important estimates. Numbers in parentheses indicate the $p$-values.

\begin{tabular}{|c|c|c|c|c|c|c|c|c|c|c|c|c|c|c|c|}
\hline$\#$ & & Constant & MKT & SMB & HML & UMD & $R^{\text {tech }}$ & $R^{\text {tech }} *$ Term & $R^{\text {tech }} *$ Ind & $R^{t e c h} * c a y$ & Term & Ind & cay & $\mathrm{R}^{2}$ & JT test \\
\hline \multirow[t]{4}{*}{1} & $b$ & 0.98 & 11.11 & & & & -107.87 & 592.58 & 475.04 & -585.01 & 4.86 & 6.93 & -34.79 & $53.9 \%$ & 31.02 \\
\hline & $t$-stat $(b)$ & $(1.54)$ & $(1.53)$ & & & & $(-2.82)$ & $(0.83)$ & $(0.76)$ & $(-0.41)$ & $(0.35)$ & $(0.58)$ & $(-0.81)$ & & $(0.566)$ \\
\hline & $\lambda(\%)$ & 6.11 & -3.48 & & & & 2.35 & 0.08 & 0.07 & 0.00 & 1.03 & -0.20 & 0.44 & & \\
\hline & $t$-stat $(\lambda)$ & $(4.54)$ & $(-2.88)$ & & & & (3.05) & (2.39) & $(1.74)$ & $(0.46)$ & $(0.89)$ & $(-0.19)$ & $(0.44)$ & & \\
\hline \multirow[t]{4}{*}{2} & $b$ & -0.16 & 6.97 & & & & & & & & 16.45 & 17.45 & 12.22 & $11.0 \%$ & 107.96 \\
\hline & $t$-stat $(b)$ & $(-0.31)$ & $(1.33)$ & & & & & & & & $(1.36)$ & $(2.05)$ & $(0.60)$ & & $(0.000)$ \\
\hline & $\lambda(\%)$ & 2.69 & -0.14 & & & & & & & & -0.88 & -1.13 & -0.24 & & \\
\hline & $t$-stat $(\lambda)$ & $(2.56)$ & $(-0.12)$ & & & & & & & & $(-0.92)$ & $(-1.28)$ & $(-0.45)$ & & \\
\hline \multirow[t]{4}{*}{3} & $b$ & 1.77 & -4.99 & -2.41 & 1.02 & -5.61 & -90.85 & 557.09 & 1025.71 & -2148.84 & 7.36 & -28.14 & -61.75 & $92.0 \%$ & 13.25 \\
\hline & $t$-stat $(b)$ & (1.23) & $(-0.34)$ & $(-0.11)$ & $(0.05)$ & $(-0.36)$ & $(-1.72)$ & $(0.57)$ & (1.23) & $(-0.93)$ & $(0.28)$ & $(1.22)$ & $(-1.44)$ & & $(0.899)$ \\
\hline & $\lambda(\%)$ & 6.64 & -4.05 & 0.35 & 1.40 & 2.33 & 1.45 & 0.05 & 0.03 & 0.01 & 1.05 & 1.03 & 0.23 & & \\
\hline & $t$-stat $(\lambda)$ & (3.36) & $(-1.93)$ & $(0.65)$ & $(2.08)$ & (3.15) & (2.49) & $(2.20)$ & $(0.83)$ & $(0.90)$ & $(0.85)$ & $(0.76)$ & $(0.34)$ & & \\
\hline \multirow[t]{4}{*}{4} & $b$ & 2.04 & -11.21 & 15.74 & -12.17 & 0.30 & & & & & 6.40 & -37.43 & -44.82 & $85.2 \%$ & 22.11 \\
\hline & $t$-stat $(b)$ & $(1.54)$ & $(-0.62)$ & $(0.59)$ & $(-0.64)$ & $(0.02)$ & & & & & $(0.24)$ & $(-1.54)$ & $(-0.98)$ & & $(0.629)$ \\
\hline & $\lambda(\%)$ & 6.31 & -3.70 & 0.21 & 1.27 & 2.02 & & & & & 0.51 & 1.34 & -0.09 & & \\
\hline & $t$-stat $(\lambda)$ & $(3.43)$ & $(-1.82)$ & $(2.05)$ & $(2.05)$ & $(3.17)$ & & & & & $(0.44)$ & $(0.91)$ & $(-0.15)$ & & \\
\hline
\end{tabular}


Table 5. Testing results: When consumption growth and cay are considered

This table reports the testing results of Cochrane's procedure based on the GMM $t$-statistics. The testing assets considered include FF 25 portfolios, ten momentum portfolios, and ten R\&D portfolios. In Panel A, we consider a linear SDF model including FF3, UMD, cay, $\Delta \mathrm{C}$, $\Delta \mathrm{C} \cdot c a y$, and $R^{\text {tech }}$. In Panel B, we consider a linear SDF model including MKT, cay, $\Delta \mathrm{C}, \Delta \mathrm{C} \cdot c a y$, and $R^{\text {tech }} . \Delta \mathrm{C}$ denotes consumption growth. We conduct the JT test to examine if the SDF model is rejected and the JT difference test to examine if the existence of $R^{\text {tech }}$ improves the explanation of stock returns. Numbers in parentheses indicate the $p$-values.

\begin{tabular}{|c|c|c|c|c|c|c|c|c|c|c|c|c|c|}
\hline \multicolumn{2}{|l|}{$\#$} & Constant & MKT & SMB & HML & UMD & cay & $\Delta \mathrm{C}$ & $\Delta C \cdot c a y$ & $R^{\text {tech }}$ & JT test & $\mathrm{R}^{2}$ & JT diff \\
\hline \multicolumn{14}{|c|}{ Panel A } \\
\hline \multirow[t]{4}{*}{1} & $b$ & 0.823 & 3.128 & & & & 12.976 & 66.863 & -331.723 & -57.476 & 70.73 & $36.1 \%$ & 61.76 \\
\hline & $t$-stat $(b)$ & 0.94 & 1.37 & & & & 0.24 & 0.43 & -0.35 & -1.86 & $(0.001)$ & & $(0.000)$ \\
\hline & $\lambda(\%)$ & 6.002 & -3.513 & & & & -0.754 & 0.042 & -0.002 & 2.300 & & & \\
\hline & $t$-stat $(\lambda)$ & 3.02 & -1.92 & & & & -0.71 & 0.26 & -0.65 & 2.73 & & & \\
\hline \multirow[t]{4}{*}{2} & $b$ & 0.724 & 2.836 & & & & 10.436 & 21.334 & 800.125 & & 107.31 & $22.0 \%$ & \\
\hline & $t$-stat $(b)$ & 1.12 & 1.34 & & & & 0.23 & 0.26 & 1.19 & & $(0.000)$ & & \\
\hline & $\lambda(\%)$ & 4.252 & -1.892 & & & & -1.078 & -0.056 & -0.007 & & & & \\
\hline & $t$-stat $(\lambda)$ & 3.47 & -1.52 & & & & -1.66 & -0.41 & -0.30 & & & & \\
\hline \multicolumn{14}{|c|}{ Panel B } \\
\hline \multirow[t]{4}{*}{3} & $b$ & 2.045 & 0.035 & -3.036 & -5.859 & -6.156 & -23.081 & -117.110 & 168.123 & -36.14 & 88.86 & $58.9 \%$ & 24.37 \\
\hline & $t$-stat (b) & 2.41 & 0.01 & -0.85 & -1.40 & -1.93 & -0.70 & -0.89 & 0.03 & -2.93 & $(0.000)$ & & $(0.000)$ \\
\hline & $\lambda(\%)$ & 2.697 & -0.301 & 0.060 & 1.115 & 2.167 & -0.199 & 0.162 & 0.000 & 1.373 & & & \\
\hline & $t$-stat $(\lambda)$ & 2.38 & -0.23 & 0.12 & 1.72 & 3.23 & -0.424 & 1.00 & 0.06 & 2.86 & & & \\
\hline \multirow[t]{4}{*}{4} & $b$ & 2.192 & 2.076 & -4.583 & -4.761 & -6.974 & -14.759 & -185.873 & 449.029 & & 111.23 & $55.7 \%$ & \\
\hline & $t$-stat (b) & 2.72 & 0.73 & -1.33 & -1.48 & -2.57 & -0.54 & -1.47 & 1.13 & & $(0.000)$ & & \\
\hline & $\lambda(\%)$ & 2.083 & 0.252 & -0.005 & 1.097 & 2.105 & -0.447 & 0.157 & -0.002 & & & & \\
\hline & $t$-stat $(\lambda)$ & 1.95 & 0.19 & -0.01 & 1.72 & 3.22 & -0.93 & 0.98 & -0.75 & & & & \\
\hline
\end{tabular}


Table 6. Testing results: FF25

This table reports the testing results of Cochrane's procedure based on the GMM $t$-statistics. The testing assets considered include FF 25 portfolios, ten momentum portfolios, and ten R\&D portfolios. In Panel A, we test the SDF model that includes MKT and $R^{\text {tech }}$. In Panel B, we test the SDF model that includes FF3, UMD, and $R^{\text {tech }}$. t-statistics are reported in parentheses. We conduct the JT test to examine if the SDF model is rejected and the JT difference test to examine if the existence of $R^{\text {tech }}$ improves the explanation of stock returns. Sample period is 1981Q4-2007Q3.

\begin{tabular}{|c|c|c|c|c|c|c|c|c|c|}
\hline \multicolumn{2}{|l|}{ \# } & Constant & MKT & SMB & HML & $R^{\text {tech }}$ & $\mathrm{R}^{2}$ & JT test & JT diff \\
\hline \multicolumn{10}{|c|}{ Panel A } \\
\hline \multirow[t]{4}{*}{1} & $b$ & 1.044 & 4.663 & & & -40.550 & $47.6 \%$ & 45.92 & 29.70 \\
\hline & $t$-stat $(b)$ & $(5.72)$ & $(2.00)$ & & & $(-1.88)$ & & $(0.002)$ & $(0.000)$ \\
\hline & $\lambda(\%)$ & 6.852 & -3.688 & & & 1.735 & & & \\
\hline & $t$-stat $(\lambda)$ & $(3.88)$ & $(-2.52)$ & & & $(2.41)$ & & & \\
\hline \multirow[t]{4}{*}{2} & $b$ & 0.889 & 2.987 & & & & $35.1 \%$ & 93.81 & \\
\hline & $t$-stat $(b)$ & (16.26) & (1.47) & & & & & $(0.000)$ & \\
\hline & $\lambda(\%)$ & 4.840 & -1.877 & & & & & & \\
\hline & $t$-stat $(\lambda)$ & $(3.82)$ & $(-1.48)$ & & & & & & \\
\hline \multicolumn{10}{|c|}{ Panel B } \\
\hline \multirow[t]{4}{*}{3} & $b$ & 0.814 & 8.962 & -5.472 & 1.545 & -12.832 & $69.2 \%$ & 56.65 & 1.59 \\
\hline & $t$-stat $(b)$ & $(3.40)$ & $(2.00)$ & $(-1.74)$ & $(0.46)$ & $(-0.88)$ & & $(0.000)$ & $(0.207)$ \\
\hline & $\lambda(\%)$ & 6.784 & -2.846 & 0.086 & 1.373 & 0.885 & & & \\
\hline & $t$-stat $(\lambda)$ & $(3.12)$ & $(-2.12)$ & $(0.16)$ & (1.90) & (1.74) & & & \\
\hline \multirow[t]{4}{*}{4} & $b$ & 0.990 & 3.498 & -5.091 & -2.497 & & $67.6 \%$ & 65.33 & \\
\hline & $t$-stat $(b)$ & (11.55) & $(1.25)$ & $(-2.08)$ & $(-1.01)$ & & & $(0.000)$ & \\
\hline & $\lambda(\%)$ & 6.836 & -4.370 & 0.134 & 1.310 & & & & \\
\hline & $t$-stat $(\lambda)$ & (3.54) & $(-2.48)$ & $(0.24)$ & (1.74) & & & & \\
\hline
\end{tabular}


Table 7. Testing results: Market-technology 25

This table reports the testing results of Cochrane's procedure based on the GMM $t$-statistics. The testing assets are 25 portfolios based on market betas and technology betas that are formed ex ante. In each June, we regress all stocks' returns on market returns and one-quarterly ahead patent shocks, as technology prospects, using the past 60 months. Then, we rank all stocks based on the market betas and technology betas, respectively, and record the market quintile and technology quintile of each stock. Lastly, we form 25 portfolios (independently) based on each stock's market quintiles and technology quintiles based on past 60 months and hold these portfolios over the following year. In Panel A, we test the SDF model that includes MKT and $R^{\text {tech }}$. In Panel B, we test the SDF model that includes FF3, UMD, and $R^{\text {tech }}$. $\mathrm{t}$-statistics are reported in parentheses. We conduct the JT test to examine if the SDF model is rejected and the JT difference test to examine if the existence of $R^{\text {tech }}$ improves the explanation of stock returns. Sample period is 1981Q4-2007Q3.

\begin{tabular}{|c|c|c|c|c|c|c|c|c|c|c|}
\hline \# & & Constant & MKT & SMB & HML & UMD & $R^{\text {tech }}$ & $\mathrm{R}^{2}$ & JT test & JT diff \\
\hline \multicolumn{11}{|c|}{ Panel A } \\
\hline \multirow[t]{4}{*}{1} & $b$ & 1.044 & 0.323 & & & & -16.53 & $28.5 \%$ & 20.80 & 13.38 \\
\hline & $t$-stat $(b)$ & $(12.33)$ & $(0.19)$ & & & & $(-2.18)$ & & $(0.533)$ & $(0.000)$ \\
\hline & $\lambda(\%)$ & 3.190 & -0.521 & & & & 0.702 & & & \\
\hline & $t$-stat $(\lambda)$ & $(3.37)$ & $(-0.50)$ & & & & $(1.82)$ & & & \\
\hline \multirow[t]{4}{*}{2} & $b$ & 0.984 & -0.331 & & & & & $2.7 \%$ & 25.41 & \\
\hline & $t$-stat $(b)$ & (18.70) & $(-0.17)$ & & & & & & $(0.329)$ & \\
\hline & $\lambda(\%)$ & 2.458 & 0.199 & & & & & & & \\
\hline & $t$-stat $(\lambda)$ & $(2.38)$ & $(0.16)$ & & & & & & & \\
\hline \multicolumn{11}{|c|}{ Panel B } \\
\hline \multirow[t]{4}{*}{3} & $b$ & 0.854 & 2.718 & 3.307 & 4.335 & 3.436 & -18.385 & $38.0 \%$ & 18.06 & 11.62 \\
\hline & $t$-stat (b) & $(3.89)$ & $(0.78)$ & $(0.61)$ & $(0.75)$ & (1.086) & $(-1.72)$ & & $(0.519)$ & $(0.001)$ \\
\hline & $\lambda(\%)$ & 3.906 & -1.172 & -0.566 & -0.435 & -0.468 & 0.742 & & & \\
\hline & $t$-stat $(\lambda)$ & $(3.36)$ & $(-0.94)$ & $(0.52)$ & $(-0.38)$ & $(-0.34)$ & $(1.76)$ & & & \\
\hline \multirow[t]{4}{*}{4} & $b$ & 0.754 & 3.868 & 1.205 & 5.898 & 2.103 & & $11.5 \%$ & 22.13 & \\
\hline & $t$-stat $(b)$ & $(4.57)$ & (1.17) & $(0.20)$ & (1.09) & $(0.74)$ & & & $(0.334)$ & \\
\hline & $\lambda(\%)$ & 3.620 & -0.882 & -0.365 & -0.825 & -0.247 & & & & \\
\hline & $t$-stat $(\lambda)$ & $(3.27)$ & $(-0.70)$ & $(-0.33)$ & $(-0.75)$ & $(-0.20)$ & & & & \\
\hline
\end{tabular}


Table 8. Testing results over 1963Q1-2007Q3

We extend the technology factor back to 1963Q1 using constant loadings for base assets. This table reports the testing results of Cochrane's procedure based on the GMM $t$-statistics. In Panel A, the testing assets considered include FF 25 portfolios, ten momentum portfolios, and ten R\&D portfolios. In Panel B, the testing assets are FF25 portfolios. t-statistics are reported in parentheses. We conduct the JT test to examine if the SDF model is rejected and the JT difference test to examine if the existence of $R^{\text {tech }}$ improves the explanation of stock returns.

\begin{tabular}{|c|c|c|c|c|c|c|c|c|c|c|}
\hline \# & & Constant & MKT & SMB & HML & UMD & $R^{\text {tech }}$ & $\mathrm{R}^{2}$ & JT test & JT diff \\
\hline \multicolumn{11}{|c|}{ Panel A: FF 25 portfolios, ten momentum portfolios, and ten R\&D portfolios } \\
\hline \multirow[t]{4}{*}{1} & $b$ & 1.206 & -4.458 & -5.098 & -7.372 & -6.389 & -78.221 & $77.3 \%$ & 77.67 & 4.29 \\
\hline & $t$-stat $(b)$ & $(14.62)$ & $(-1.78)$ & $(-1.78)$ & $(-4.00)$ & $(-4.61)$ & $(-1.59)$ & & $(0.000)$ & $(0.038)$ \\
\hline & $\lambda(\%)$ & 0.195 & 1.639 & 0.689 & 0.969 & 2.168 & 0.068 & & & \\
\hline & $t$-stat $(\lambda)$ & $(0.17)$ & $(1.43)$ & $(1.37)$ & $(1.90)$ & $(4.31)$ & (1.38) & & & \\
\hline \multirow[t]{4}{*}{2} & $b$ & 1.320 & -3.907 & -2.661 & -6.447 & -6.563 & & $74.7 \%$ & 88.52 & \\
\hline & $t$-stat $(b)$ & $(16.45)$ & $(-1.61)$ & $(-1.14)$ & $(-3.91)$ & $(-5.41)$ & & & $(0.000)$ & \\
\hline & $\lambda(\%)$ & 0.195 & 1.610 & 0.677 & 0.944 & 2.280 & & & & \\
\hline & $t$-stat $(\lambda)$ & $(0.18)$ & $(1.44)$ & $(1.36)$ & $(1.78)$ & (4.49) & & & & \\
\hline
\end{tabular}

Panel B: FF25 portfolios

\begin{tabular}{|c|c|c|c|c|c|c|c|c|c|}
\hline \multirow[t]{3}{*}{3} & $\begin{array}{c}b \\
t \text {-stat }(b)\end{array}$ & $\begin{array}{l}0.928 \\
(9.05)\end{array}$ & $\begin{array}{l}-2.223 \\
(-0.61)\end{array}$ & $\begin{array}{l}-6.017 \\
(-1.77)\end{array}$ & $\begin{array}{l}-6.332 \\
(-2.25)\end{array}$ & $\begin{array}{r}-118.207 \\
(-1.82)\end{array}$ & $82.8 \%$ & $\begin{array}{r}38.32 \\
(0.008)\end{array}$ & $\begin{array}{r}6.17 \\
(0.013)\end{array}$ \\
\hline & $\lambda(\%)$ & 0.042 & 1.577 & 0.837 & 1.265 & 0.202 & & & \\
\hline & $t$-stat $(\lambda)$ & $(0.03)$ & $(1.00)$ & $(1.72)$ & $(2.66)$ & (1.89) & & & \\
\hline 4 & $b$ & 0.990 & 3.498 & -5.091 & -2.497 & & $80.3 \%$ & 58.02 & \\
\hline & $t$-stat $(b)$ & (11.55) & $(1.25)$ & $(-2.08)$ & $(-1.01)$ & & & $(0.000)$ & \\
\hline & $\lambda(\%)$ & 2.930 & -1.351 & 0.780 & 1.414 & & & & \\
\hline & $t$-stat $(\lambda)$ & $(2.24)$ & $(-1.07)$ & (1.59) & $(2.80)$ & & & & \\
\hline
\end{tabular}


Table 9. Testing results: 10 I/A portfolios and 10 profitability portfolios

This table reports the testing results of Cochrane's procedure based on the GMM $t$-statistics. We test the SDF model using 10 investment-to-asset portfolios in Panel A and using 10 profitability (ROA) portfolios in Panel B. t-statistics are reported in parentheses. We conduct the JT test to examine if the SDF model is rejected and the JT difference test to examine if the existence of $R^{\text {tech }}$ improves the explanation of stock returns. Sample period is 1981Q4-2007Q3.

\begin{tabular}{|c|c|c|c|c|c|c|c|c|c|}
\hline \# & & Constant & MKT & SMB & HML & $R^{t e c h}$ & $\mathrm{R}^{2}$ & JT test & JT diff \\
\hline \multicolumn{10}{|c|}{ Panel A: 10 investment-to-asset portfolios } \\
\hline \multirow[t]{4}{*}{1} & $b$ & 1.361 & -0.130 & -0.215 & -11.702 & -60.104 & $81.7 \%$ & 2.00 & 8.00 \\
\hline & $t$-stat $(b)$ & $(3.41)$ & $(-0.02)$ & $(-0.03)$ & $(-1.56)$ & $(-2.06)$ & & $(0.845)$ & $(0.004)$ \\
\hline & $\lambda(\%)$ & 3.857 & -1.760 & -0.574 & 2.787 & 1.499 & & & \\
\hline & $t$-stat $(\lambda)$ & $(1.74)$ & $(-0.80)$ & $(-0.67)$ & $(2.05)$ & $(2.25)$ & & & \\
\hline \multirow[t]{4}{*}{2} & $b$ & 0.978 & 0.508 & 0.270 & -2.431 & & $41.7 \%$ & 12.28 & \\
\hline & $t$-stat $(b)$ & (7.59) & $(0.11)$ & $(0.05)$ & $(-0.59)$ & & & $(0.056)$ & \\
\hline & $\lambda(\%)$ & 1.517 & 0.545 & -0.749 & 1.141 & & & & \\
\hline & $t$-stat $(\lambda)$ & $(0.99)$ & $(0.34)$ & $(-1.00)$ & (1.10) & & & & \\
\hline
\end{tabular}

Panel B: 10 profitability portfolios

3

t-stat $(b)$$$
\lambda(\%)
$$

4.095

$(2.10)$

\begin{tabular}{cc}
$t$-stat $(\lambda) \quad(2.10)$ \\
\hline$b$ & 0.793
\end{tabular}

4

t-stat (b)

(5.43)

$\lambda(\%)$

4.464

(2.24)

$t$-stat $(\lambda)$
2.800

8.200

2.577

$-9.764$

$97.1 \%$

2.20

$(0.820)$

$(0.801)$
(0.47) (0.84)

(0.88) (-0.68)

$-0.191 \quad 0.469$

$-2.711$

$$
\text { (-1.40) } \quad(-1.70)
$$

-0.22) (0.65)

$5.081 \quad 4.604$

$(0.78)$

(0.42)

3.722

(1.22)

$-3.778$

$-2.166$

$-0.161$

$(-1.57)$

$(-1.17)$

$(-0.19)$ 
Table 10. Testing results: using 10 industry portfolios and the market portfolio as base assets

This table reports the testing results of Cochrane's procedure based on the GMM $t$-statistics. Note that, we use 10 industry portfolios and the market portfolio as the base assets in constructing the tracking factor. The testing assets considered include FF 25 portfolios, ten momentum portfolios, and ten R\&D portfolios. In Panel A, we test the SDF model that includes MKT and $R^{\text {tech }}$. In Panel B, we test the SDF model that includes FF3, UMD, and $R^{\text {tech }}$. t-statistics are reported in parentheses. We conduct the JT test to examine if the SDF model is rejected, and the JT difference test to examine if the existence of $R^{\text {tech }}$ improves the explanation of stock returns. Sample period: 1981Q4-2007Q3.

\begin{tabular}{|c|c|c|c|c|c|c|c|c|c|c|}
\hline \# & & Constant & MKT & SMB & HML & UMD & $R^{\text {tech }}$ & $\mathrm{R}^{2}$ & JT test & JT diff \\
\hline \multicolumn{11}{|c|}{ Panel A } \\
\hline \multirow[t]{4}{*}{1} & $b$ & 1.121 & -0.059 & & & & -82.742 & $25.0 \%$ & 103.09 & 118.57 \\
\hline & $t$-stat (b) & $(7.36)$ & $(-0.03)$ & & & & $(-3.00)$ & & $(0.000)$ & $(0.000)$ \\
\hline & $\lambda(\%)$ & 3.480 & -1.269 & & & & 0.949 & & & \\
\hline & $t$-stat $(\lambda)$ & $(3.10)$ & $(-1.09)$ & & & & $(3.36)$ & & & \\
\hline \multirow[t]{4}{*}{2} & $b$ & 0.956 & 0.684 & & & & & $2.9 \%$ & 196.20 & \\
\hline & $t$-stat (b) & $(17.25)$ & $(0.32)$ & & & & & & $(0.000)$ & \\
\hline & $\lambda(\%)$ & 2.864 & -0.495 & & & & & & & \\
\hline & $t$-stat $(\lambda)$ & $(2.20)$ & $(-0.36)$ & & & & & & & \\
\hline
\end{tabular}

\section{Panel B}

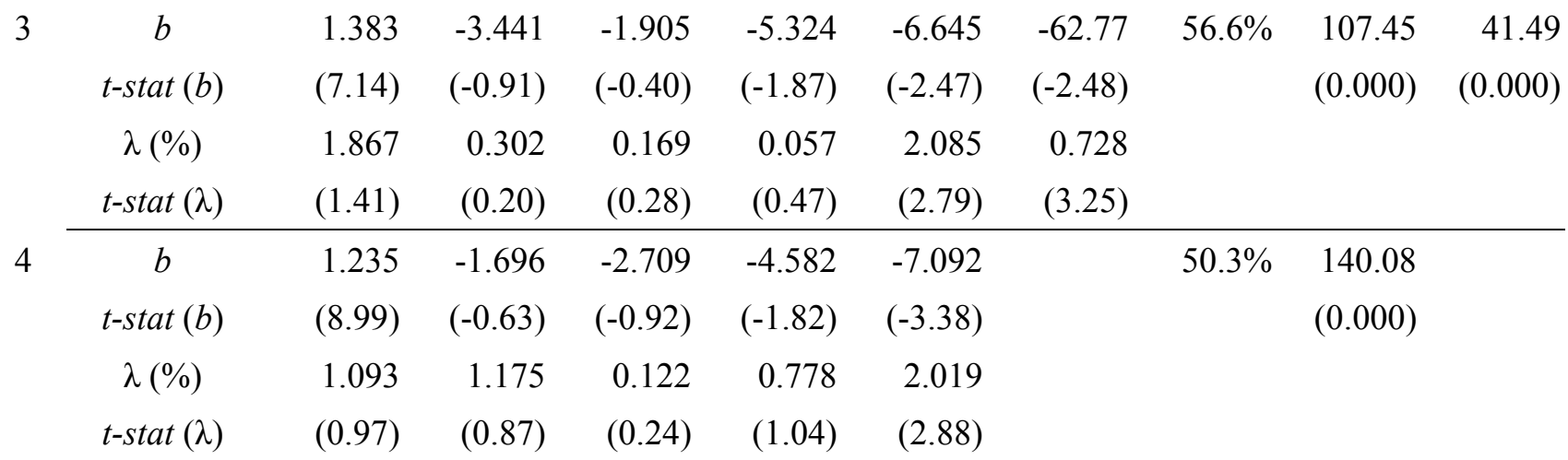




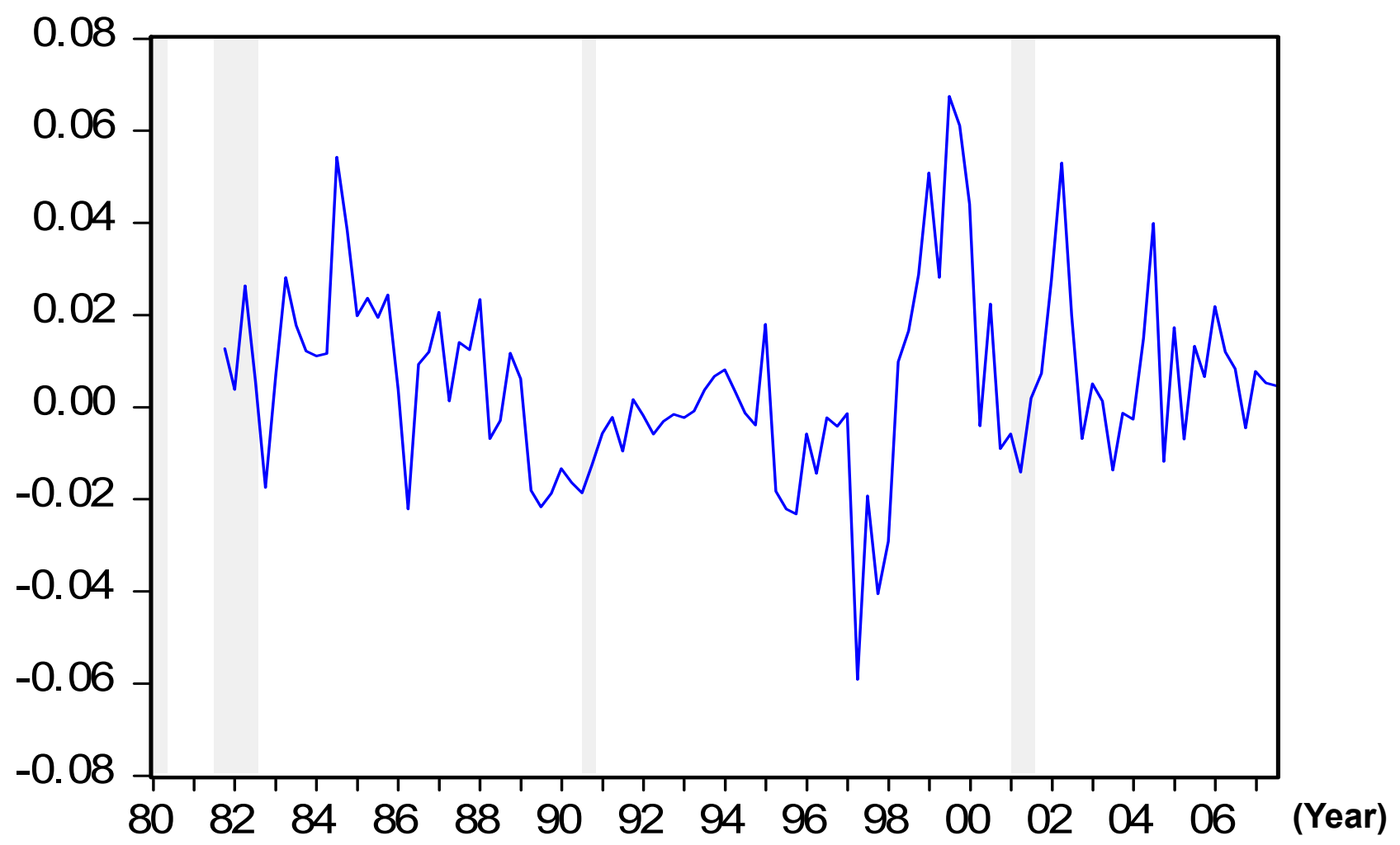

Figure 1. The time series of the technology factor

We plot the technology factor $\left(R^{\text {tech }}\right)$ with a solid line. The shaded periods denote NBER contraction periods (from one peak to its following trough). 

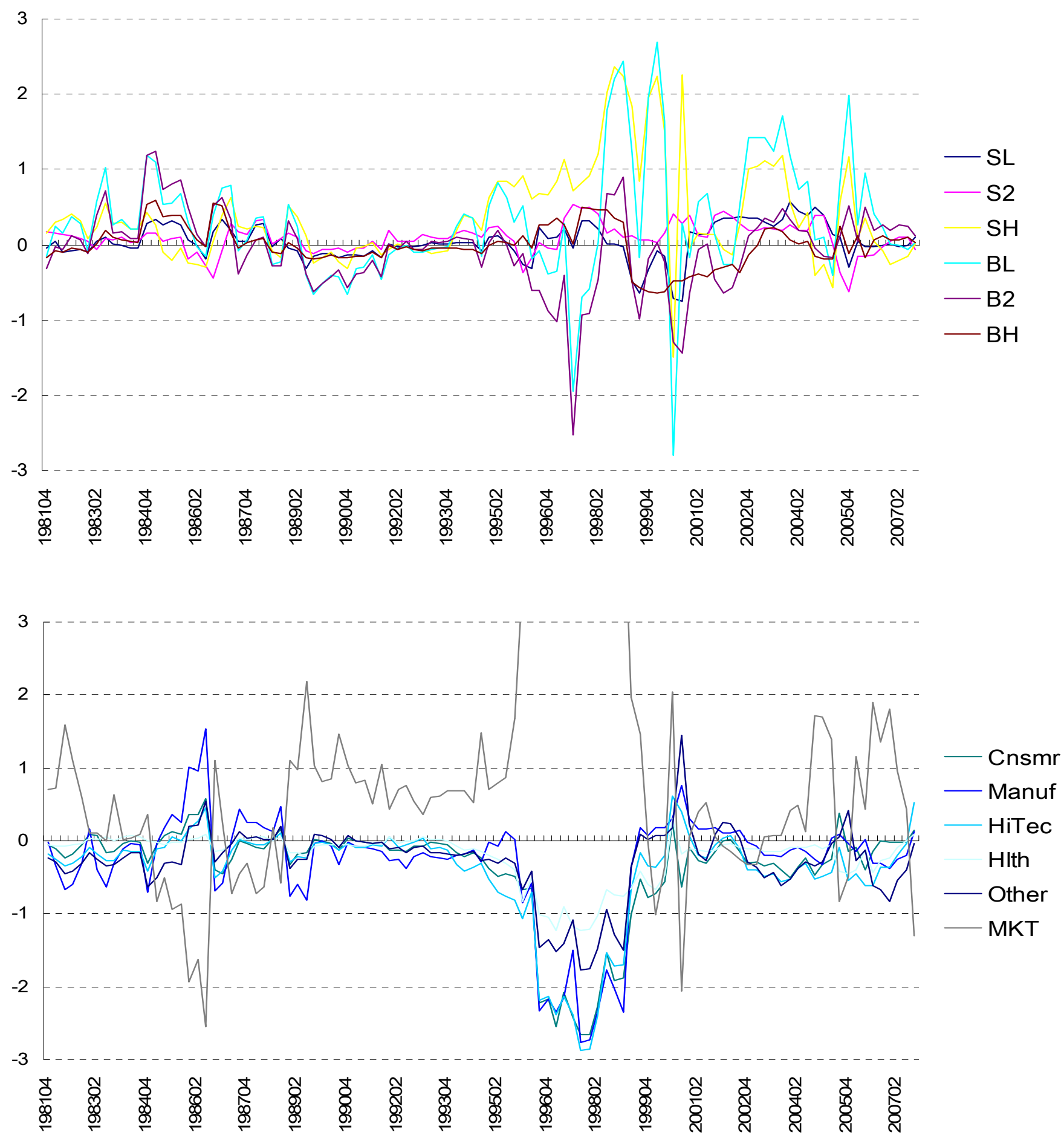

\begin{tabular}{|c|c|c|c|c|c|c|c|c|c|c|c|c|}
\hline & SL & S2 & $\mathrm{SH}$ & $\mathrm{BL}$ & B2 & $\mathrm{BH}$ & Cnsmr & Manuf & HiTec & Hlth & Other & MKT \\
\hline M & 0.040 & 0.093 & 0.378 & 0.307 & -0.058 & -0.008 & -0.377 & -0.301 & -0.419 & -0.207 & -0.285 & 0.040 \\
\hline St. dev. & 0.233 & 0.194 & 0.656 & 0.789 & 0.537 & 0.263 & 0.686 & 0.760 & 0.684 & 0.330 & 0.488 & 0.233 \\
\hline
\end{tabular}

Figure 2. The projection loadings $\left(a_{1, t}\right)$ of 12 base asset portfolios in constructing the technology factor In this figure, we plot the time series of base asset portfolios' projection loadings $\left(a_{1, t}\right)$ in constructing the technology factor. The table below the figure provides the means and standard deviations of the projection loadings. Note that the loadings of MKT over 1997Q3-1998Q1 are over three, so they are not plotted (10.27, 10.88, and 10.68, respectively). 

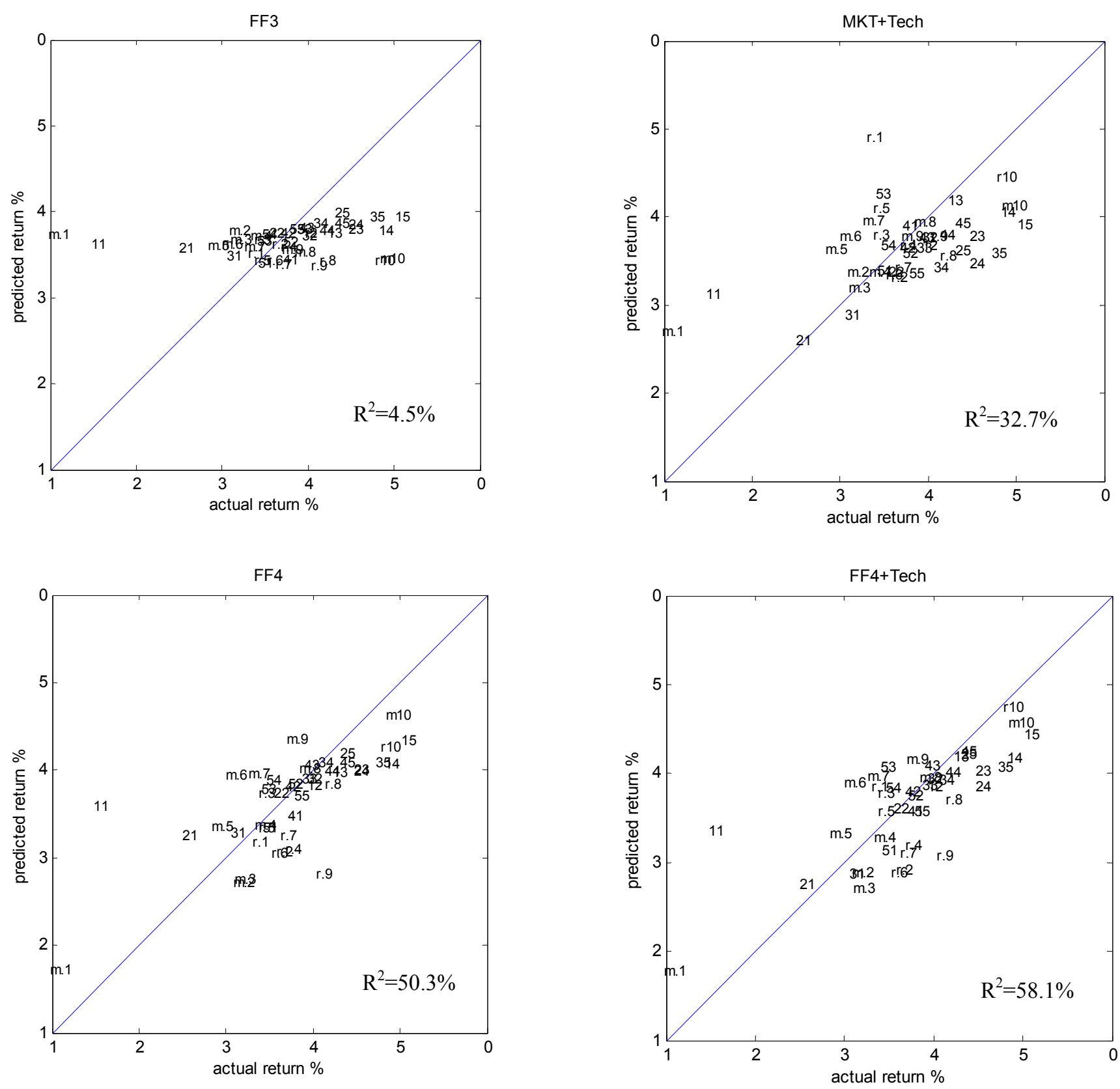

Figure 3. Actual returns and predicted returns implied by the SDF models considered

This figure demonstrates how well a model explains the cross-sectional variation of the excess returns of FF35 plus R\&D10 portfolios. The title of each figure indicates the factors included in the SDF models. FF3 denotes MKT, SMB, and HML. FF4 denotes MKT, SMB, HML, and UMD. Tech denotes the technology factor. All dots are labeled in two-digit. In FF25 portfolios, the first digit indicates the size (1-smallest and 5-biggest) and the second digit indicates the book-to-market ratio (1-lowest or "growth" and 5-highest or "value"). For example, the dot labeled 15 denotes the portfolio composed of firms with sizes in the smallest decile and book-to-market ratios in the highest decile. For ten momentum portfolios, we use " $\mathrm{m}$ " before numbers 1 (the lowest momentum) to 10 (the highest momentum). For ten $R \& D$ portfolios, we use " $r$ " before numbers 1 (the lowest R\&D intensity) to 10 (the highest R\&D intensity). Dots located exactly on the diagonal line suggest that the excess returns of these portfolios are perfectly predicted by corresponding SDF models. 


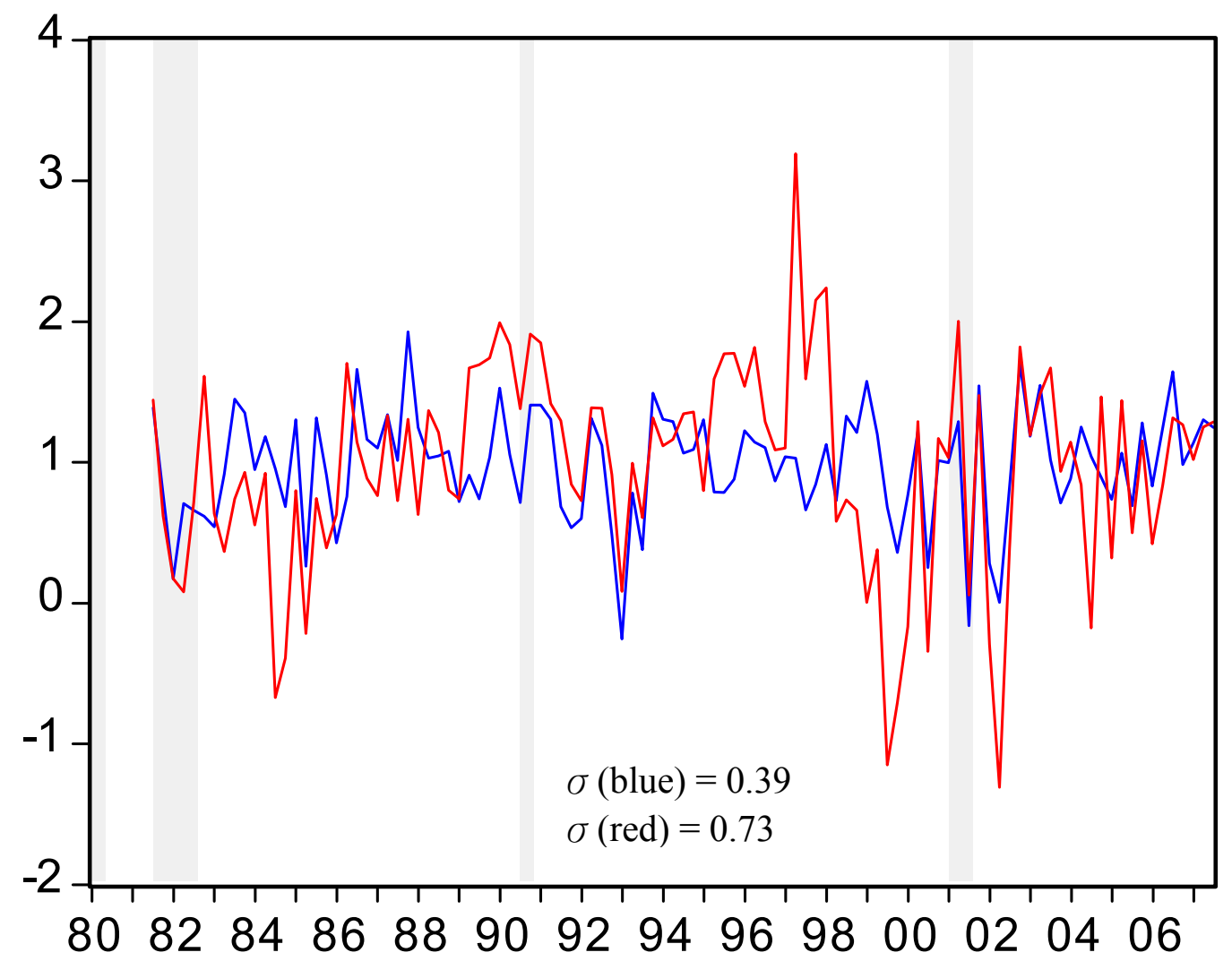

(Year)

Figure 4. The time series of the stochastic discount factor (SDF)

The red line denotes the time series of the SDF based on FF4 (MKT, SMB, HML, and UMD) plus $R^{\text {tech }}$ (\#3 of Table 2). The blue line denotes the time series of the SDF based on FF4 (MKT, SMB, HML, and UMD) (\#4 of Table 2). Therefore, the horizontal difference between these two lines can be used as a measure of the influence of technology prospects on the SDF. The shaded periods denote NBER contraction periods (from one peak to its following trough). 